\title{
REVIEW
}

\section{Crop responses and management strategies under shade and drought stress}

\author{
I. SHAFIQ ${ }^{*, * *}$, S. HUSSAIN ${ }^{*, * *}$, B. HASSAN ${ }^{* * *}$, A. RAZA ${ }^{\#}$ I. AHMAD ${ }^{*, * *}$, M.A. ASGHAR ${ }^{\# \text {, }}$

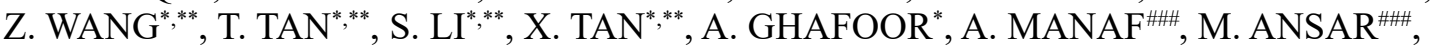 \\ F. YANG ${ }^{*, * *,+}$, and W. YANG ${ }^{*, * *}$
}

College of Agronomy, Sichuan Agricultural University, 211-Huimin Road, Wenjiang District, 611130 Chengdu, China*

Sichuan Engineering Research Centre for Crop Strip Intercropping System, Key Laboratory of Crop Ecophysiology and Farming System in Southwest China (Ministry of Agriculture), Sichuan Agricultural University, Chengdu, China $^{* *}$

Rice Research Institute and Key Laboratory for Major Crop Diseases, Sichuan Agricultural University at Wenjiang, Chengdu, China ${ }^{* * *}$

CAS Key Laboratory of Mountain Ecological Restoration and Bioresource Utilization, Ecological Restoration Biodiversity Conservation Key Laboratory of Sichuan Province, Chengdu Institute of Biology, Chinese Academy of Sciences, P.O. Box 416, 610041 Chengdu, China

Agricultural Institute, ELKH Centre for Agricultural Research, 2462 Martonvásár, Brunszvik u. 2, Hungary

Department of Agronomy, Pir Mehr Ali Shah Arid Agriculture University, Rawalpindi, Punjab, Pakistan ${ }^{\# \#}$

\begin{abstract}
The occurrence of shade and drought stress either individually or simultaneously causes altered morphophysiological and molecular responses in crops. Nevertheless, responses of crop plants to combined shade and drought stress are unique as compared to those of individually occurring stress which urges need to study and identify distinctions, commonalities, and the interaction between responses of plants to these concurrent stress factors. In the present review, we outlined currently available knowledge on responses of plants to shade and drought stress on a shared as well as the unique basis and tried to find a common thread potentially underlying these responses. Then, we briefly described some plausible mitigation strategies to cope with these stresses along with future perspectives. A deeper insight into plant responses to co-occurring shade and drought stress will help us to generate crops with broad-spectrum stress tolerance and increased resilience to such stresses in high planting densities or intercropping systems, thus, ensuring food security.
\end{abstract}

Keywords: cooccurring stress; crop; individual stress; morphophysiological and molecular responses; stress management.

\section{Highlights}

- Crop responses to co-occurring and individual shade and drought stress

- Mitigation strategies to cope with stresses along with future perspectives

- Deeper knowledge of plant responses to co-occurring stresses is indispensable
Received 16 August 2021

Accepted 16 November 2021

Published online 14 December 2021

Corresponding author

e-mail: f.yang@sicau.edu.cn

Abbreviations: DEG - differentially expressed genes; LEA - late embryogenesis abundant proteins; PHY - phytochrome; PIFs phytochrome-interacting factors; $P_{\mathrm{N}}-$ net photosynthetic rate; QTL - quantitative trait locus; R:FR - red:far-red; ROS - reactive oxygen species; RWC - relative water content; SARs - shade avoidance responses; WUE - water-use efficiency; $\psi_{\mathrm{w}}$ - plant leaf water potential. Acknowledgments: This work was supported by the National Nature Science Foundation (No. 32071963), Program on Industrial Technology System of National Soybean (No. CARS-04-PS19), and the Project on Science and Technology of Chengdu City (No. 2020-YF09-00033-SN).

Conflict of interest: The authors declare that they have no conflict of interest. 


\section{Introduction}

In the present era of global warming and climate change, plants on Earth are continuously being challenged by their surrounding environment, forcing them to acclimate for the sustenance of their survival. In addition, the continuous deterioration of limited available arable land area by humans is further threatening global food security. As there is a rapid increase in the world population, the demand for food is also increasing likewise, which necessitates the need to grow more resilient plants to feed the increasing population. Under such critical circumstances, one alternative is to grow crop plants at higher densities or in intercropping systems, while keeping intact the individual plant productivity (Courbier and Pierik 2019). However, this option is not as straightforward as it seems to be, as various challenges come with this option, the most important being the shade stress characterized by low red:far-red (R:FR) ratio and low light intensity, as a result of which plants compete with each other for light (Hussain et al. 2019a).

$\mathrm{R}$ and FR light are perceived by plants via a family of phytochrome (PHY) photoreceptors that exist in two interconvertible forms; $\mathrm{Pfr}$ - which is active FR light-absorbing form and $\mathrm{Pr}-$ which is inactive R lightabsorbing form. Five different phytochromes (PHYA-E) have been characterized so far in Arabidopsis thaliana. PHY B is considered as the main modulator of low R:FR-mediated shade avoidance responses (SARs) along with PHY D and E. FR light inactivates phytochromes, reduces phytochrome-mediated degradation of phytochrome interacting factors, leads to rapid induction of gene expression, and triggers biosynthesis and signal transduction of numerous plant hormones, such as auxin, gibberellin, brassinosteroid, and ethylene ultimately promoting elongation growth which is a characteristic of SARs (Keuskamp et al. 2010). SARs involve regulation of metabolic and transcriptional networks which facilitates elongated growth but at the cost of enhanced apical dominance and that of leaf development, thus enabling young growing tissues to get away from shade (Franklin 2008). In general, shade inhibits leaf growth as the proportion of biomass distributed to leaves in comparison to stem decreases under shade stress (Wu et al. 2017). Reduced stomatal conductivity and density are also typical of shade conditions that lead to poor transport of $\mathrm{CO}_{2}$ (Tan et al. 2021). Furthermore, the movement of electrons from PSII to PSI is blocked and the number and activity of enzymes participating in Calvin cycle changes (Shafiq et al. 2021), i.e., decreased level of reduced thioredoxins in chloroplast stroma is associated with an increased level of oxidized CP12 (chloroplast peptide: a small nuclear-encoded chloroplast protein), which forms PRK/DAPH/CP12 complex leading to reduced activity of glyceraldehyde-3-phosphate dehydrogenase and phosphoribulokinase, thereby affecting carbon fixation rate in Calvin-Benson cycle under shade conditions (LópezCalcagno et al. 2014).

With higher planting densities or cultivation of crops in intercropping systems, the challenge of water deficit stress or drought comes, which severely restricts crop growth (Iqbal et al. 2019). Drought stress is usually represented by the reduction of plant leaf water potential $\left(\psi_{\mathrm{w}}\right)$, closure of stomata, reduced cell growth and enlargement, reduced turgor pressure, and reduced relative water content (RWC) (Soltys-Kalina et al. 2016). It is well documented that drought alters numerous physiological and biochemical processes, i.e., photosynthesis, chlorophyll biosynthesis, metabolism of various nutrients, uptake of ions and translocation of elements, respiration, and carbohydrates metabolism (Ashraf and Harris 2013). Additionally, it results in the production of reactive oxygen species (ROS), further damaging the normal functioning of the photosynthetic machinery, leading to serious yield reductions (Green-Tracewicz et al. 2011). At a molecular level, it modulates the production of various genes, transcription factors, heat-shock proteins, aquaporins, late embryogenesis abundant (LEA) proteins, dehydrins, etc. (Kaur and Asthir 2017).

When shade and drought stress co-occur simultaneously, physiological, structural, and biochemical changes occur in plants at the leaf as well as the whole plant level (Holmgren 2000). Such stresses might result in different plant responses, i.e., additive, synergistic or antagonistic (Zhang et al. 2011), that may or may not hamper plant growth and vary from species to species. Research work on shade (Chen et al. 2019, 2020; Ferroni et al. 2021) and drought (Lawlor and Tezara 2009, Zivcak et al. 2014a, Anjum et al. 2017), occurring as individual stress factors in several crops, is well cited in the literature. However, not much attention has been given to their combined effects and whether the crop responses to both of these stresses are shared or unique also remains ambiguous (Shafiq et al. 2020). An understanding of the responses of plants to cooccurring stress factors is necessary to enhance plants' adaptation under field conditions. The present review is an effort to comprehend the current understanding of the effect of shade and drought stress, individually on crop plants. Furthermore, it sheds light on the shared and unique responses of crop plants to shade and drought stress and discusses some feasible alleviation strategies to survive these stresses and to minimize the harm caused by these stresses to the crop plants.

\section{Plant responses to shade stress}

The incidence of shade stress at any stage of plant growth negatively affects the growth and development of the plant. The intensity of injury owing to the stress, however, depends on the magnitude of the stress and its duration as well as the plant growth stage. The consequences of shade stress on plant's morphophysiological, biochemical, as well as molecular processes are elicited below.

\section{Plant phenotypes}

Shade negatively affects various morphological and growth parameters in crops, such as winter wheat (Triticum aestivum; Li et al. 2010), rice (Oryza sativa; Liu et al. 2014), soybean (Hussain et al. 2019a), and maize (Gao et al. 
2017). Shade results in a smaller leaf area by administering the proliferation and enlargement of cells and reduces the number and size of the cell, hence, decreasing the size of the plant leaf (Wu et al. 2017). It results in thinner leaves with thinner palisade tissues (Valladares and Niinemets 2008), leading to a structure that is not conducive to the dissolution and transport of $\mathrm{CO}_{2}$ (Terashima et al. 2001). Smaller and thinner leaves in response to shade stress is a common characteristic observed in many plant species, such as soybean (Wu et al. 2017), sunflower (Helianthus annus; Granier and Tardieu 1999), Chenopodium album (Yano and Terashima 2004), rice (Murchie et al. 2005), Arabidopsis (Kozuka et al. 2005), Eurya japonica (Mishio and Kawakubo 2015), Juglans regia (Atanasova et al. 2003), Carya illinoinensis (Lombardini et al. 2009), and tomato (Solanum lycopersicum; Fan et al. 2013). Such leaf structure results in lower harvesting of light (Yang et al. 2014, Wu et al. 2017). The low R:FR ratio under shade also affects leaf angle as shade on the adaxial side promotes the elongation of the cells on that side through adjustment of Pfr content, thus changing the leaf angle to increase the light interception in leaf (Fujita et al. 2008).

Leaf cuticle and epidermal appendages like trichomes play an important protecting role against light interception (Karabourniotis et al. 2021). In comparison to sun leaves, shade leaves have a thinner cuticle membrane (Wu et al. 2020). Non-glandular trichomes form dense layers on plant organ surfaces and have distinct optical characteristics (Werker 2000). Liakoura et al. (1997) found that trichome density and its UV-B protective potential are affected by shading. Under low irradiance or low angles of incidence, trichome layers may limit light harvesting for photosynthesis. Trichomes may thus influence light propagation into the mesophyll, thereby influencing the characteristic of the internal light microenvironment and the extent of light-saturated photosynthesis in the internal cell layers (Gorton and Vogelmann 1996).

Low R:FR ratio causes stem elongation as it enhances the expression of flavin monooxygenase which increases the content of auxin that is then transported from leaves to stem, thus leading to extension of internodes as well an increase in plant height (Liu et al. 2019). Furthermore, a low R:FR ratio also increases gibberellin content which accelerates the cell division and cell elongation of the stem, thus leading to increased plant height (Kamiya and García-Martínez 1999). It decreases the diameter of the stem since more carbon is allocated to the stem and petiole elongation thus impairing the development of roots and leaves (Gommers et al. 2013). Shade also decreases stem strength by reducing the biosynthesis of lignin which is a major component of the cell walls, resulting in weak and elongated stems having poor mechanical strength and susceptibility to lodging leading to loss of yield (Hussain et al. 2020a).

Shade also affects the root morphology; it reduces the root length, surface area, and volume (Hussain et al. 2019 b). Generally, under shade conditions, the growth of roots is reduced more than the growth of the aerial parts as the photosynthates are distributed preferentially to shoots during leaf extension to increase the interception of light
(Hébert et al. 2001, Gommers et al. 2013, Gundel et al. 2014). This ultimately leads to a decrease in the root/shoot ratio (Zhou et al. 2020). Light not only influences root morphology by regulating the synthesis and partitioning of photosynthates but also acts as a signal to directly regulate root growth (van Gelderen et al. 2018a). For example, farred light detection in the shoot of Arabidopsis regulates lateral root growth via the HY5 transcription factor (van Gelderen et al. 2018b).

Shade reduces the growth of plants along with its metabolic activities which influence the agronomic and yield parameters of the plants. During the rice filling stage, it causes a decrease in yield and degrades the grain quality (Chen et al. 2019). In another study, shade increased the chalkiness by delaying the development of caryopsis and disturbing the characteristics of starch in rice grains thus reducing the market price and quality of rice grain (Deng et al. 2018). In winter wheat, a shade between jointing and maturity stage caused yield reduction (Li et al. 2010). Similarly, in cotton (Gossypium hirsutum), shade stress between flowering and boll-opening stage resulted in the decrease of cotton boll's number and mass, strength of the fiber, and the micronaire that led to poor yield and quality of cotton (Chen et al. 2017). However, the effect of shade on yield parameters of crops may differ based on the shade's duration and magnitude, crop growth stage, and local ecological environment.

\section{Photosynthetic performance}

Shade is well reported to influence the performance of plant photosynthesis and other leaf gas-exchange parameters. Under shade stress, light-intercepting and utilization ratio as well as the activity of PSII increases, but the photosynthetic capacity is inhibited as transport of energy from PSII to PSI is hindered (Zivcak et al. 2014b) (Fig. 1). Shade stress in soybean, during the vegetative growth phase, disrupted the normal photosynthetic rate due to decreased energetic pressure generation at PSII, thus minimizing electron transport rate, reducing the amount of ATP produced as well as the Rubisco activity. It affected the photochemical activity, assimilation of $\mathrm{CO}_{2}$ and decreased the quantum efficiency of PSII and quantum yield (Hussain et al. 2019b). Poor photosynthetic rates in crop plants grown under shade are also attributed to (1) poor mesophyll and stomatal conductance of $\mathrm{CO}_{2}$, (2) impaired chloroplast development, and (3) hindered photosynthesis due to inhibited leaf growth caused by controlled cell multiplication (Wu et al. 2017).

Shade results in lower leaf and canopy temperature together with decreased transpiration rate and stomatal conductance. It might also reduce stomatal opening (Knapp and Smith 1990) as in guard cells the content of abscisic acid increases and binds to soluble receptors triggering the closing of stomata (McCourt and Creelman 2008). Activation of abscisic acid receptor enhances the activity of respiratory burst oxidases due to increased phosphorylation (Mustilli et al. 2002) which leads to a brief outbreak of ROS in the stomatal guard cells (Pei et al. 2000) that open calcium ion influx channels (Mittler 


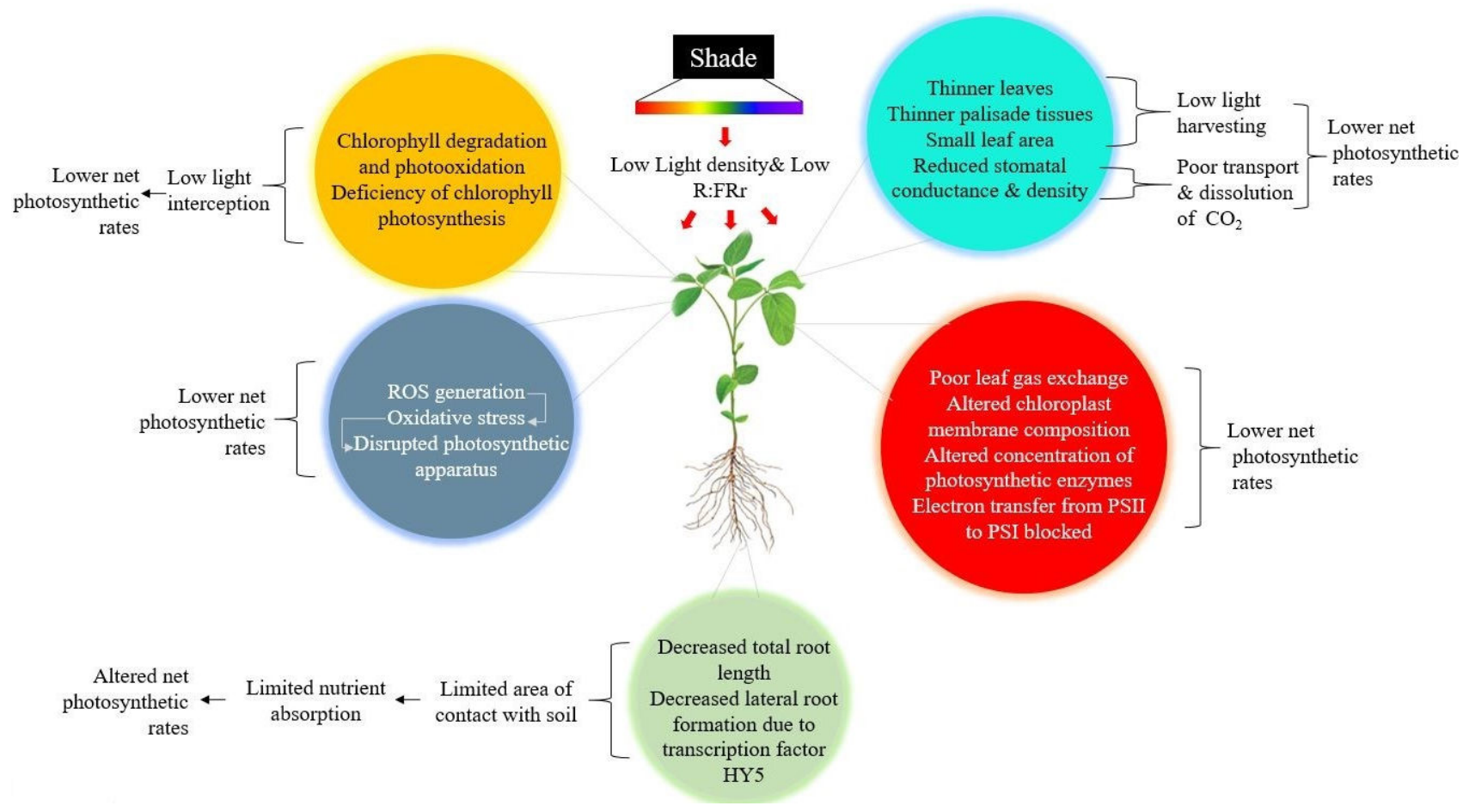

Fig. 1. Effect of shade stress on net photosynthetic rate.

and Blumwald 2015), thus activating cell membrane's ion efflux channels. Such alterations in the concentration of ions cause water efflux, increasing the flaccidity of guard cells which causes stomata to close (Chen et al. 2010). Shade also affects the Chl antenna size. Under low light conditions, when $\mathrm{Chl} a / b$ ratio decreases and the light-harvesting center to PS-core ratio increases, the $\mathrm{Chl}$ antenna size increases, and this serves as a dynamic compensation response to shade conditions (Leong and Anderson 1984, Melis 1991).

\section{Reactive oxygen species and antioxidant activity}

When plants experience shade, they undergo oxidative stress and enhanced ROS production. The stress leads to increased levels of photorespiration and enhances the activity of the mitochondrial electron transport chain (mETC) (Blokhina et al. 2003, Lawlor and Tezara 2009). Earlier research reports the enhanced ROS production in plants under shade stress (Apel and Hirt 2004, Volkov et al. 2006, Zhu et al. 2017). Shade results in increased auxin contents and auxin-regulated ROS production has also been reported; it plays a role in root gravitropism (Joo et al. 2001). To mitigate the oxidative damage and maintain cellular homeostasis, plants produce an elaborate arsenal of enzymatic (superoxide dismutase, ascorbate peroxidase, peroxidase, catalase, glutathione reductase, glutathione S-transferase, guaiacol peroxidase, etc.) and nonenzymatic (reduced and oxidized glutathione, ascorbic acid, $\alpha$-tocopherol, and carotenoids) antioxidants under unfavourable conditions such as shade and drought stress
(Shafiq et al. 2021). These antioxidants not only interrupt the cascades of uncontrolled oxidation by ROS but also help in the maintenance of an appropriate balance between their production and removal that allows an optimum functioning of photosynthesis (Foyer 2018). Various enzymatic and nonenzymatic antioxidants have been known for inducing shade tolerance as reported in pine needles (Anderson et al. 1992), ginger (Ghasemzadeh et al. 2010), spruce (Polle and Rennenberg 1992, Doulis et al. 1993), olive (Mohammad et al. 2019), Taxus $\times$ media cv. Tauntonii (Verhoeven et al. 2005), etc. The high contents of antioxidants in response to stresses show that they contribute towards stress tolerance in plants.

\section{Plant-related gene and protein expression}

Shade modulates plant responses at the molecular level as well. Under shade stress, phytochromes perceive altered R:FR light while cryptochromes sense changes in light to control the adaptive developmental approaches (Casal 2012). This is followed by signal transduction which is then cascaded through phytochrome interacting factors (PIFs), circadian clock protein TOC1, circadian clock basic helixloop-helix protein PIL1, and various transcription factors belonging to DELLA families to activate the alterations of gene expression (light signal genes, hormone-related genes, and stress-induced genes), and prompt series of shade-avoidance syndrome responses (Salter et al. 2003, Wang et al. 2011, Gendron et al. 2012, Gallemí et al. 2016). The end-of-day far-red treatment induces many auxin or brassinosteroid responsive genes and both auxin [big and 
shade avoidance 3 (sav3)/tryptophan aminotransferase of Arabidopsis 1 (taa1)] and brassinosteroid [rotundifolia 3 (rot3)] mutant showed decreased shade-induced expression of genes as well as the petiole elongation (Kozuka et al. 2010). Li et al. (2017) reported that shaded conditions downregulated the expression of gibberellin biosynthesis genes in a shade-tolerant mutant of perennial ryegrass compared to wild type which demonstrated the function of gibberellin in dwarfism and tolerance to shade. The microarray analysis disclosed that shade regulated the expression of genes that were involved in cell wall carbohydrate metabolism, responses of auxin, and the flavonoids in the stem of tomato (Cagnola et al. 2012). Similarly, RNA-Seq based transcriptome analysis of the conifers grown under shade stress showed gene regulations on the signalling of hormones and biosynthesis of pigments (Ranade et al. 2019). Shade stress in peanut (Arachis hypogaea) downregulated the expression of various genes for photosynthesis pathways, and the key genes in the metabolism of sucrose and starch, and the hormonal signal pathways (Chen et al. 2020). Heavy shade in soybean lead to expressional downregulation of key genes participating in the lignin biosynthesis which reduced the lodging resistance (Wen et al. 2020). To conclude, shade profoundly alters a plant's genetic expression.

\section{Plant responses to drought stress}

Similar to shade stress, the incidence of drought stress at any stage of plant growth also negatively affects the growth and development of plants. The consequences of drought stress on morphophysiological, biochemical, as well as molecular processes in plants are elicited below.

\section{Morphological parameters}

The key crop phenotypic indicators of drought stress include plant height and leaf area. Drought results in shorter plants and restricted leaf growth (Paredes et al. 2014). It hampers the flow of water from the xylem to other elongating cells as well as causes reduced turgor pressure that results in a reduction of cell division, cell elongation, and cell expansion leading to a smaller leaf area in crop plants (Pereyra-Irujo et al. 2008, Skirycz et al. 2010). Reduced leaf expansion is helpful for plants under such stress, as it reduces the area of leaf exposed, which results in reduced rates of transpiration, thus preventing water loss. Drought increases the endogenous abscisic acid content which accelerates the leaf senescence process as observed in rice (Ray et al. 1983). Similarly, increased concentrations of ethylene under water stress were correlated with increased senescence and abscission of leaves in Vicia faba (El-Beltagy and Hall 1974). This mechanism of accelerated senescence and abscission in old leaves of mature plants under water deficit stress is called leaf area adjustment (Mahajan and Tuteja 2005).

Water deficit stress also alters root morphology and architecture and causes a reduction in root to shoot ratio (Shi et al. 2015, Anjum et al. 2016a). It has multiple effects on root growth, for example, Catharanthus roseus and sunflower enhanced their root length when exposed to water deficit stress (Tahir et al. 2002, Jaleel et al. 2008) while no effect was observed in maize and wheat. The increase in root length under water deficit might be attributed to increased root abscisic acid content (Manivannan et al. 2007). However, drought effects on root architecture vary between drought-tolerant and sensitive plants (Manschadi et al. 2006). In general, extensive and prolific root system enhances the ability of plant in sustaining growth and yield in a drought environment (Chandra Babu et al. 2001). Nevertheless, at regular but lower amounts of precipitation, the moisture is not sufficient enough to make deeper fractions of soil wet, hence a subsurface root architecture is more desirable under such conditions.

Drought in legumes limits flower and pod production, enhances flower and pod abortion rate, reduces seed size, thus, causing a dramatic loss of seed yield (Fang et al. 2010). Water deficit in soybean greatly reduces branch number and the total yield of seed (Frederick et al. 2001). A 33\% drought-induced reduction in global chickpea (Cicer arietinum) production is expected (Kashiwagi et al. 2015). In comparison to legume or root crops (such as Dioscorea alata, Beta vulgaris, etc.), cereals had lower drought-induced yield reduction (Daryanto et al. 2017). Drought caused a yield reduction in other crops, such as cotton, peanut, sunflower, wheat, and maize (Tahir et al. 2002, Kamara et al. 2003, Pettigrew 2004, Vasantha et al. 2005, Barnabás et al. 2008, Furlan et al. 2012).

\section{$\mathrm{C}_{3}$ and $\mathrm{C}_{4}$ plant photosynthesis}

Lack of water availability affects various metabolic processes including photosynthesis. It causes a significant reduction in $\mathrm{C}_{3}$ and $\mathrm{C}_{4}$ photosynthesis (Fig. 2). The core processes of $\mathrm{C}_{3}$ and $\mathrm{C}_{4}$ photosynthesis are the same, including light-harvesting complexes, electron transport components, and the $\mathrm{C}_{3}$ cycle. As a result, $\mathrm{C}_{3}$ and $\mathrm{C}_{4}$ plants are expected to respond similarly to drought stress; nevertheless, the two photosynthetic types are significantly different, which may result in differing responses. $\mathrm{C}_{4}$ plant leaves have a $\mathrm{CO}_{2}$-concentrating mechanism that provides them with greater water-use efficiency (WUE) contrary to $\mathrm{C}_{3}$ plants. However, it is still debatable if $\mathrm{C}_{4}$ plants having higher WUE can withstand more drought stress in comparison to $\mathrm{C} 3$ plants. Similarly, though the $\mathrm{CO}_{2}$-concentrating mechanism provides better-buffering capacity to $\mathrm{C}_{4}$ photosynthesis against $\mathrm{CO}_{2}$ shortages due to limited closing of stomata during drought, yet $\mathrm{C}_{4}$ photosynthesis biochemistry is considered to be at least as sensitive or even more sensitive as compared to $\mathrm{C}_{3}$ photosynthesis (Ghannoum 2009). Generally, drought reduces the leaf area and causes the closing of stomata that lowers the leaf intercellular $\mathrm{CO}_{2}$ concentration, thus imposing limitations on $\mathrm{CO}_{2}$ assimilation. Drought stress also lowers mesophyll conductance (Genty et al. 1989, Flexas et al. 2004). The mesophyll conductance refers to the flow of $\mathrm{CO}_{2}$ from the intercellular air spaces to the carboxylation site in the chloroplasts of mesophyll cells, and it takes into account the intricate routes of the cell wall, plasma membrane, chloroplast envelope, and stromal 


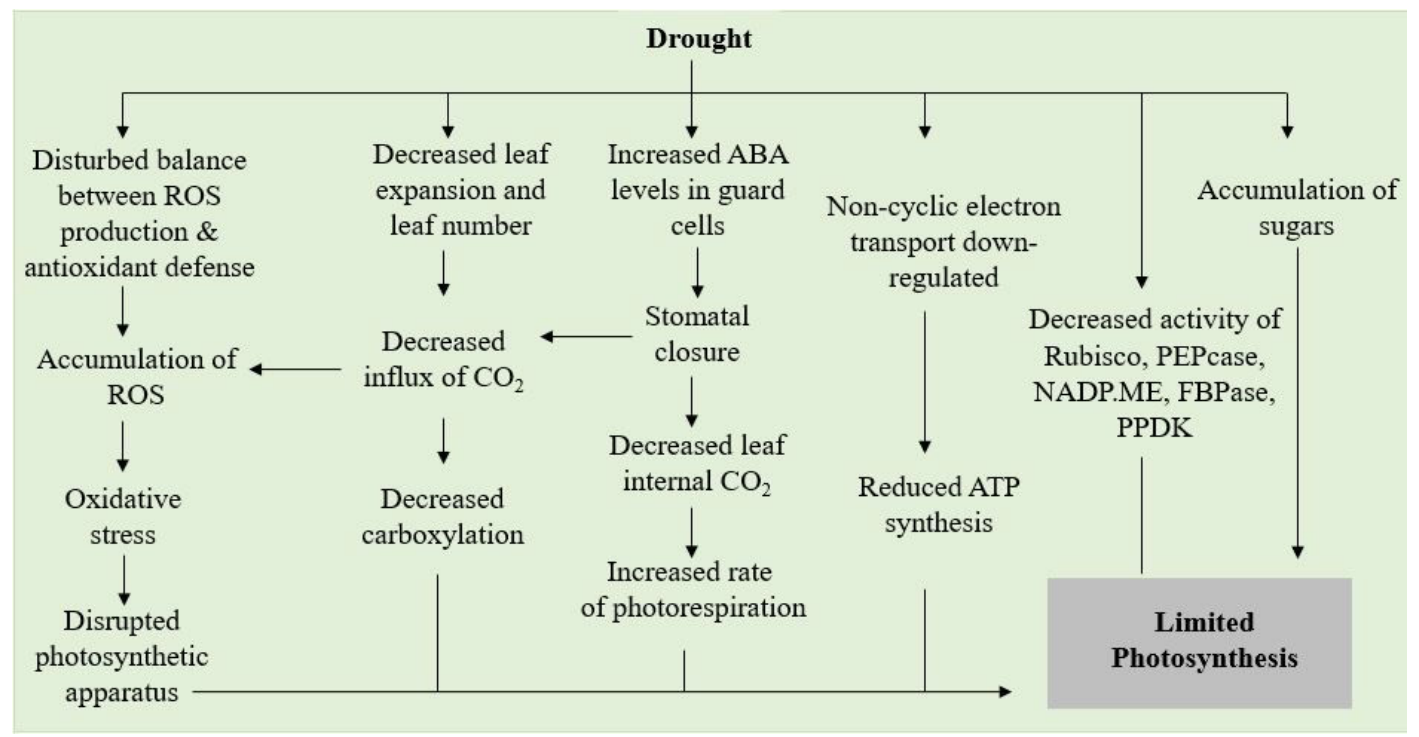

Fig. 2. Effect of drought stress on photosynthesis. ABA - abscisic acid; ATP - adenosine 5'-triphosphate; FBPase - fructose1,6-bisphosphatase; ME - malic enzyme; NAD - nicotinamide adenine dinucleotide phosphate; PEPcase - phosphoenolpyruvate carboxylase; PPDK - pyruvate phosphate dikinase; ROS - reactive oxygen species.

thylakoids (Ethier et al. 2006). Recent research suggests that mesophyll conductance plays an important function in photosynthetic regulation (Fleck et al. 2010, Ferroni et al. 2021). Reduced mesophyll conductance values during water stress may lead to a delayed restoration of net photosynthetic rate, making it a critical limiting factor in net photosynthetic rate recovery (Olsovska et al. 2016). It is assumed that mesophyll conductance accounts for up to $40 \%$ of the $\mathrm{CO}_{2}$ diffusional constraints on entire photosynthesis (Warren 2008). Stomatal closure in response to drought stress results in a disproportion of photochemical activity at PSII and electron requirement for the process of photosynthesis (Runion et al. 1997, Zivcak et al. 2014a), hence increasing the vulnerability to photodamage (He et al. 1995, Guo et al. 2018). It damages and reduces the synthesis of photosynthetic pigments (Oneto et al. 2016) and declines the Rubisco activity (Lawlor and Tezara 2009), thus, limiting the plant photosynthesis. Another reason for the reduced net photosynthetic rate in response to water deficit is the generation of ROS. Water deficit limits intercellular $\mathrm{CO}_{2}$ concentration. This accumulates the components of reduced photosynthetic electron transport which can potentially reduce the molecular oxygen. This generates ROS which damage the photosynthetic apparatus (Hussain et al. 2019c). To conclude, drought has detrimental effects on the light-harvesting mechanism and photosynthetic apparatus in plants.

\section{Plant water and nutrient relations}

Water deficit significantly lowers the RWC, turgor pressure, $\psi_{\mathrm{w}}$, and $E$ which is well documented in various crop species (Siddique et al. 2000, Liu et al. 2004, Reddy et al. 2004, Nayyar and Gupta 2006, Yang and Miao 2010, de Campos et al. 2011). It also hinders mineral nutrient uptake and translocation from roots to shoots (Suriyagoda et al. 2014). It reduces the growth of root per unit of root length and root biomass, as well as the rate of inflow of the nutrients (Kuchenbuch et al. 1986). Water scarcity affects the cation active transport and membrane permeability which reduces the cation absorption through roots ( $\mathrm{Hu}$ and Schmidhalter 2005). Drought also affects the metabolism of the nutrients, for instance, it hinders the functioning of enzymes that take part in the assimilation of nutrients (Ashraf and Iram 2005). It might also cause micronutrient deficiency for manganese, iron, and molybdenum ( $\mathrm{Hu}$ and Schmidhalter 2005), however, as soon as the soil is well watered, these micronutrients are converted into more soluble and reduced forms to be used by plants (Havlin et al. 2016). In conclusion, the occurrence of drought stress in plants decreases nutrient availability, uptake, translocation, and their metabolism.

\section{Reactive oxygen species, antioxidants, organic solutes, and phytohormones}

Drought results in excessive ROS generation which serves as an adaptive mechanism in stressed plants (Hossain et al. 2021). Excessive ROS generation causes oxidative injury in plant cells (Sgherri et al. 1993, Boo and Jung 1999). It enhances the ROS generation through various ways, e.g., limited $\mathrm{CO}_{2}$ fixation reduces the $\mathrm{NADP}^{+}$production via the Calvin cycle which lessens the photosynthetic electron transport chain (Cruz de Carvalho 2008). It enhances the photorespiratory pathway, particularly when RuBP oxygenation is at maximum because of the restrictions on $\mathrm{CO}_{2}$ fixation. Furthermore, under conditions of water deficit, photorespiration contributes to more than $70 \%$ of total $\mathrm{H}_{2} \mathrm{O}_{2}$ production (Noctor et al. 2002). Various 
enzymatic and nonenzymatic antioxidants have been known for inducing drought tolerance as reported in rice (Sharma and Dubey 2005), transgenic rice, and tobacco (Nicotiana tabacum) (Badawi et al. 2004, Prashanth et al. 2008), in wheat (Keleş and Öncel 2002), transgenic wheat, soybean, and petunia (Petunia hybrida; Yamada et al. 2005, Simon-Sarkadi et al. 2006, Vendruscolo et al. 2007), transgenic tobacco (Yan et al. 2003), cotton (Ratnayaka et al. 2003), beans (Türkan et al. 2005), etc. Plants also produce enzymatic and nonenzymatic antioxidants to inhibit ROS accumulation. Droughttolerant wheat genotypes can reduce $\mathrm{O}_{2}$ oxidative damage by maintaining higher contents of carotenoids during drought stress, according to a previous study by Balouchi (2011). Under drought stress, Ma et al. (2014) found that the amount of flavonoids in wheat leaves is increased due to the higher expression of flavonoid biosynthesis genes. Apart from ROS and antioxidants, plants produce a variety of compatible organic solutes in response to drought stress (Boscaiu and Fita 2020). Plant cells use osmotic adjustment to preserve water status in their tissues during drought stress. The biosynthesis of osmotically dynamic substances, such as proline (Farooq et al. 2017), glycine betaine (Gupta et al. 2014), sugar alcohols, soluble sugars, organic acids (Farshadfar et al. 2008), chloride ions, calcium, and potassium, is involved in osmotic adjustment (Farshadfar et al. 2008). Moreover, plants produce phytohormones such as abscisic acid to control stomatal opening through guard cells and protect plants from excessive water loss thus facilitating plant acclimatization to drought stress (Schachtman and Goodger 2008).

\section{Responses at the molecular level}

Molecular alterations in response to environmental stresses negatively affect the growth and development of crops. Several genes are upregulated or downregulated by water deficit conditions. Water deficit alters the level of expression of LEA (dehydrin-type genes) as Sivamani et al. (2000) found; tolerance to drought was enhanced in rice roots and wheat leaves by overexpression of barley group 3 LEA gene $H V A 1$. Furthermore, synthesis of the molecular chaperone (Close 1997, Bhargava and Sawant 2013), dehydration-responsive element (having A/GCCGAC as a core sequence) (Seki et al. 2001), homeodomain leucine zipper protein's expression (that interacts with CaCBFIB) (Mahajan and Tuteja 2005), and expression of H1-S (histone H1variant which is known to function in regulating stress modulated genes and aid closing stomata) (Scippa et al. 2004, Bhargava and Sawant 2013) are all reported to be regulated under drought conditions. Abscisic acid production in roots is also regulated under drought stress. It is transported to shoots which causes the closure of stomata, thus restricting the growth of plants (Mittler and Blumwald 2015). Likewise, water scarcity and abscisic acid have been shown to rapidly elevate calcium levels in plant cells, activating a signalling pathway that activates a number of genes that help maintain cellular homeostasis (Sanders et al. 1999, 2002). Enhanced tolerance to drought stress was observed in rice by upregulation of Oryza sativa WRKY11 under control of the heat-shock protein 101 (HSP101) promoter (Wu et al. 2009). Drought stress upregulated miR398, whereas it reduced the level of expression of $\mathrm{Cu} / \mathrm{Zn}$ SOD isoforms in peanut (Park and Grabau 2017). Similarly, drought stress regulated the gene expression of transcription factors associated to bZIP, MYB, bHLH, NF-Y, EAR, NAC, and ZPT2, AP2/ERF, HD-ZIP families (Yang et al. 2010).

\section{Plant responses to co-occurring shade and drought stress}

The morphological and physiological responses to shade and drought, including structural and biochemical variation, have been well documented at the single-leaf and whole-plant levels but what impact does the co-occurring shade and drought stress have on the plant growth, it still remains unclear. To date, there has been no consistent conclusion on this issue, but several contrasting hypotheses have been proposed. First, the trade-off hypothesis, which predicts that shade increases the effect of drought on plants. This is so as plants allocate more resources to leaves and shoots in comparison to roots under shade stress which eventually increases the light-capture capacity but reduces water absorption in plants (Smith and Huston 1990). Additional mechanisms for a trade-off have also been indicated in specific cases (Marshall 1986, Vance and Zaerr 1991, Kubiske et al. 1996). By contrast, the influential facilitation hypothesis predicts that shade might reduce air and leaf temperature, leaf vapor-pressure deficit, and oxidative stress. Thus, shading can help to alleviate the negative effects of drought on plants (Holmgren 2000) but the degree to which deep shade can be facilitative is unclear. The third hypothesis is the interplay hypothesis which suggests that drought has a relatively stronger impact under high irradiance and deep shade, with moderate shade alleviating the negative effects of drought (because of facilitation) (Holmgren et al. 1997). Finally, an independent-effects model predicts that the effects of shade and drought are independent, i.e., orthogonal, as drought reduces relative growth rate (RGR) by a given proportion at any irradiance (Sack and Grubb 2002, Sack 2004). Some limited literature available (mostly on woody seedlings) regarding the effect of co-occurring shade and drought stress on plant growth is elicited below.

\section{How plant morphophysiology responds to cooccurring shade and drought stress}

Carneiro et al. (2015) found that when shade (70\%) grown Jatropha curcas plants were subjected to long-term water deficit conditions (irrigation withheld until signs of stress, i.e., leaf tipping and wilting became evident), the biomass allocated to roots was lowered by $>40 \%$ though the root length did not change. However, the leaf size of plants grown in co-occurring shade and drought stress was considerably greater than those grown under full sun and drought environment. The reduction in biomass allocation to roots showed that exposure of Jatropha plants to co-occurring shade and drought stress could 
hamper plant development whereas larger leaf area under shade was probably due to reduced demand of evaporation in the shaded environment that led to the maintenance of leaf size in drought conditions. Amissah et al. (2015) reported that seedlings of ten different Ghanaian trees species under drought stress (withholding water for nine weeks), survived better in shade (20\% irradiance) than those in full light as better microclimatic conditions in the shaded environment under drought conditions (i.e., shade lowered the temperature of air and leaves, thus hampering overheating, and reduced the transpirational demands of plants; also shaded plants exposed to drought have higher relative water content in comparison to those plants grown under full light) enhanced the plant performance under drought conditions thus supporting facilitation hypothesis. The facilitation hypothesis was also supported by examples of red oak and yellow poplar seedlings grown in a combination of shade and drought stress (Kolb et al. 1990). When discussing the yield components, shade and drought stress occurring individually generally have negative effects on plant yield, however, when both the stresses occur simultaneously, the effect on yield is often not the same. Shade stress, in some cases, may serve useful to alleviate negative consequences of water deficit stress on the yield of crops as reported earlier in soybean (Zhang et al. 2011, Shafiq et al. 2020).

Plant photosynthetic response to co-occurring stresses might also vary in comparison to individual stress. Transpiration rate $(E)$, stomatal conductance $\left(g_{\mathrm{s}}\right)$, and net photosynthetic rate $\left(P_{\mathrm{N}}\right)$ in plants did not decrease when exposed to drought stress ( $55 \pm 2 \%$ field capacity) and low irradiance $\left(\mathrm{PPFD}=500-600 \mu \mathrm{mol} \mathrm{m} \mathrm{m}^{-2} \mathrm{~s}^{-1}\right.$ at noon) whereas a decrease was observed in plants that were kept in medium or high irradiance which depicts a positive role of shade under drought conditions (Shafiq et al. 2020) and supports the facilitation hypothesis (Holmgren 2000). The results of this research propose that the degree of influence of drought stress on a plant's photosynthetic capacity depends on the irradiance in the environment. In the co-occurrence of shade and drought stress, the production of reductants, such as glutathione reductase, thioredoxin reductase as well as ascorbate, decreased due to shade. This decreased reduction capacity is associated with increased ROS-driven oxidative damages induced by drought (Ali et al. 2005, Baier et al. 2005, Ahmed et al. 2009). The damages caused by ROS lead to numerous physiological and biochemical dysfunction in plants. Contrastingly, Asghar et al. (2020) reported lesser ROS production (under drought stress) in soybean plants exposed to shade in comparison to those grown under normal light; the possible explanation could be that shade pretreatment enhanced the exogenous auxin that played role in ROS detoxification. Furthermore, they reported that drought stress in soybean seedlings leads to increased proline content, soluble and reducing sugars, however, the increase was greater in plants under a pre-shade treatment in comparison to plants grown under normal light. This increase in osmoprotectant accumulation in shaded plants occurred due to the increment in abscisic acid contents and the enhancement of auxin contents which helped the plants in better survival under drought conditions (Pardos and Calama 2018).

\section{Which genes and proteins respond to co-occurring shade and drought stress}

In conditions of co-occurring drought and shade stress, the molecular changes that occur may or may not be the same as those which occur in response to individual stresses. For instance, in drought conditions, DELLA proteins enhance abscisic acid sensitivity in stomatal guard cells due to the inhibition of gibberellic acid biosynthesis which interferes with abscisic acid receptors, thus leading to an earlier closure of stomata in tomato plants (Nir et al. 2017). However, a beneficial function of phytochrome $B$ and DELLAs in the plant's drought tolerance may reverse under shade stress where low R:FR ratio of light causes phytochrome $\mathrm{B}$ inactivation and upregulation of gibberellic acid signalling (resulting in increased bioactive gibberellic acid) that eventually causes degradation of DELLAs (Djakovic-Petrovic et al. 2007). Hence, drought stress may lessen or diminish the advantages of shade avoidance in a field environment (Huber et al. 2004). Contrastingly, (Asghar et al. 2020) reported shade-induced expressional upregulation of $A A O 3$ and NCED3 (abscisic acid biosynthesis genes) and $A B I 4$ and $A B I 5$ (abscisic acid signalling genes), which helped to overcome the far-reaching implications of water deficit in soybean. The increased synthesis of abscisic acid could be due to high sugar contents which ultimately lead to the signalling of abscisic acid. ABI4 transcription factor performs an essential function in abscisic acid-sugar connection and its expression is upregulated by the availability of higher sugar content (Arenas-Huertero et al. 2000). Nevertheless, this predicted association between abscisic acid and sugar content together with the role of the studied genes needs to be examined further under varying environmental conditions. Most of the research available has been conducted on plant morphophysiological and molecular responses to individual stress, however, as it is obvious from the above-cited literature, further studies on the range of species (specifically field crops) are required for a profound understanding of the changes in plant responses under co-occurrence of simultaneous shade and drought stress.

\section{Management strategies for drought and shade}

Drought and shade stress adversely affect plant growth and productivity. Such effects can be managed and minimalized by various efforts.

\section{Selection and breeding strategies}

A combination of traditional, molecular, and omics-based techniques could be used to generate shade and droughttolerant genotypes (Maqbool et al. 2017). The use of molecular and biotechnological means for selecting preferred materials (such as in conventional breeding), 
along with the production of genetically engineered crops, helps assemble material for shade and water-deficit tolerance (Fig. 3). Liu et al. (2017) used metabolomic analysis of isoflavones based on the OPLS-DA (orthogonal partial least-squares discriminant analysis) model for predicting shade tolerance of soybean seedlings of various germplasm without actually conducting tedious field experiments. This provided an easier alternative for evaluating and screening shade-tolerant soybean germplasms. Yuan et al. (2012) found two important QTLs (quantitative trait loci) for plant height and ear height; qPH4 and qEH4a simultaneously at two different locations under shade and full-light treatments in maize. These QTLs were found to be insensitive to shade stress in maize cultivars, hence, it was suggested that these QTLs could be used for selecting shade-tolerant and/or high planting density-tolerant maize hybrids in maize breeding programs. Li et al. (2017) used transcriptome analysis to identify differentially expressed genes (DEGs) of a shadetolerant mutant of perennial ryegrass (Lolium perenne) called 'shadow-1' under shade stress. They found 329 DEGs that were unique to shadow-1 plants grown in a shaded environment and also the gibberellin-biosynthesis genes were downregulated compared to wild type. The data provided could be used by breeders to develop shade-tolerant dwarf ryegrass cultivars. Other physiological and morphological characteristics used for screening shade-tolerant crops include reduced elongation responses, the longevity of leaf, specific leaf area, root/shoot ratio, rate of dark respiration, and relative growth rate (Gommers et al. 2013).

In the case of drought stress conditions, the 'final grain yield' is the most commonly used parameter for screening drought-tolerant crops in the conventional breeding approach (Verulkar et al. 2010). Since yield (a quantitative trait) has low heritability, this approach remains ineffective (Ouk et al. 2006). However, a profound understanding of physiological and molecular basis might aid in targeting the key traits restricting the crop yield. QTL analysis and segregation mapping provide us with the molecular basis of tolerance to water deficit stress (Lanceras et al. 2004). Identifying QTLs involved in drought tolerance aid in MAS (marker-assisted selection) of crops with preferred characters (Rahman et al. 2011, Varshney et al. 2012). Though, a considerable number of QTLs for numerous drought-tolerant traits have already been reported, yet the discovery of epistatic QTLs and epiQTLs in the future could be potentially used for molecular breeding (Gupta et al. 2017). Apart from conventional breeding, the classical breeding approach is also in practice (Chandra Babu et al. 2003). Selecting putative drought-adaptive secondary traits in classical breeding is reported to be useful for developing drought-tolerant cultivars. Earlier, much research regarding the genetic analysis of secondary traits (i.e., root system architecture, $\psi_{\mathrm{w}}$, panicle water potential, osmotic adjustment, and RWC) has been conducted, however, such traits have low heritability just like yield under drought stress (Ludlow and Muchow 1990, Atlin and Lafitte 2002, Jongdee et al. 2002).

\section{Biological engineering technology}

At present, plants are commonly bioengineered for drought tolerance using various transgenic approaches (Bahieldin et al. 2005, Nakashima et al. 2014). The expression of involvement of $D R E B 2 A$ and $D R E B 2 B$ (drought-induced transcription factors) were found to be involved in the expression of numerous genes involved in tolerance against drought stress in crops (Cui et al. 2011, Ali et al. 2017). Responses of abscisic acid-responsive elementsbinding proteins (AREB) to water deficit at transcriptional and post-transcriptional levels were found to be also the determinants of plants' abilities to tolerate drought (Kaur and Asthir 2017). Overexpression of AtWRKY57 induced tolerance against drought stress in Arabidopsis (Li et al. 2013). Expression of AtWRKY63 and BdWRKY36 imparted tolerance against drought stress through the abscisic acid-signalling pathway in transgenic tobacco

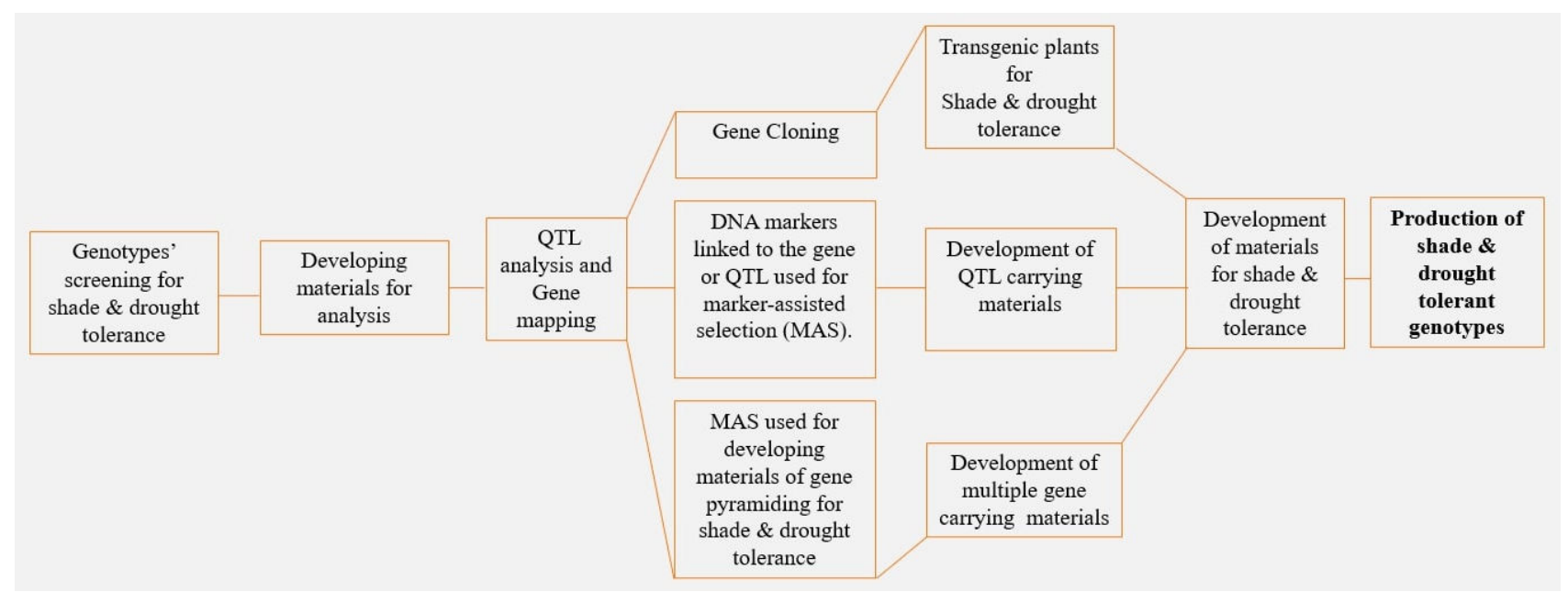

Fig. 3. Strategy for developing materials for shade and drought tolerance. 
(Sun et al. 2015). Drought tolerance was enhanced in rice by overexpression of OSLEA3-1 and OsLEA3-2 genes (Xiao et al. 2007, Duan and Cai 2012). The LEA group protein gene $H V A 1$ which (during the maturation stage of seed) accumulates in the aleurone layers and embryos of barley, increased the transgenic rice plants' tolerance against water deficit stress ( $\mathrm{Xu}$ et al. 1996). Aquaporins assist in the regulation of the plant-water relations, hence can be used to develop drought-resistant plant genotypes (Afzal et al. 2016). Considerable literature is available and shows that the transgenic expression of specific stress regulatory genes resulted in enhanced crop tolerance to drought, but the enhanced expression of these genes is also often related to growth retardation which limits its practical applications. Therefore, developing water deficitresistant crops will necessitate a profound apprehension of the genetic basis of drought tolerance along with the recognition of transcriptions factors linked to resistance to drought stress (Xiong et al. 2006).

Though much research has been conducted to identify genes responsive to individual stress, further efforts are required to identify genes expressed by both shade and drought stress concurrently. The combination of traditional breeding with modern-day techniques, i.e., genetic engineering, marker-assisted selection, and molecular breeding, will assist in developing and improving crop resistance against individual and concurrent environmental stress factors (Fleury et al. 2010).

\section{Induction of shade and drought resistance}

Resistance to shade and water deficit could be imparted in plants by taking several agronomic and physiological measures. Of these, adjustment of row configuration in the intercropping system and planting densities in the monocropping system, exogenously applied various plant growth regulators, osmoprotectants, mineral nutrients, seed priming, etc., have proven to be beneficial in mitigation of the negative implications of shade and drought stress. An account of these measures is given below.

\section{Optimum planting pattern}

Shade is not just an issue for the growth of plants growing in forest understoreys but also for the short-statured crops growing in intercropping systems or the crops growing at higher densities in the sole cropping system. In high planting densities, erect leaves serve as a vital adaption to obtain a higher leaf area index, enhancing photosynthetic rate (Sinclair and Sheehy 1999). In the case of intercropping systems, adjustment of row configuration and use of appropriate planting patterns should be taken into consideration to avoid shade stress (Maitra et al. 2021). Maize-soybean relay-intercropping has been preferred over strip intercropping which helps the shortstatured soybean crop avoid shade for most of its growth period and prevent lodging and thus yield loss (Yang et al. 2017, Fan et al. 2018). Feng et al. (2019) suggested that selecting an optimum planting pattern could help increase the interception of light and affect the distribution of light between maize and soybean rows in relay-intercropping thereby reducing the shade avoidance response in shortstatured soybean and leading to a significant improvement in productivity of the intercrops. Likewise, Raza et al. $(2019 a, b)$ also documented such results. Adjustment of planting geometry in the intercropping system helped in enhancing the water-use efficiency of the intercrops (Rahman et al. 2017a,b). In the case of monocropping, adjustment of planting densities should be taken into account to prevent the shade from neighbouring plants (Roig-Villanova and Martínez-García 2016, Fiorucci and Fankhauser 2017). Under drought stress, adjusting planting densities can help in lowering the competition of water and nutrients among plants. Higher planting densities under drought conditions increase competition for water among seedlings that can cause their death. It is preferable to use lower planting density under such conditions that increase distance among plant roots and ensure adequate water availability for each plant (Cordero et al. 2021). Selecting an optimum row to row and plant to plant distance can also help in reducing competition for water and other resources. Reduced row to row distance results in lower canopy temperature and controlled transpiration via leaf cooling pathways (Crawford et al. 2012). It will also lower ROS production and photodamage caused by high light and temperature that are usually accompanied by drought stress (Cordero et al. 2021).

\section{Application of plant growth regulators}

Various natural or synthetic plant growth regulators have been proven to have potential effects in increasing the ability of plants to acclimatize against various abiotic stresses. Pons et al. (2001) reported that shade caused a decline in leaf expansion, but cytokinin application to shaded leaves restored the leaf expansion. Tegg and Lane (2001) showed that 'Primo' (trinexapac-ethyl), a plant growth regulator, significantly improved the shade adaptation of several turfgrass species commonly used in high-quality turf surfaces. Similarly, paclobutrazol, a growth regulator and an inhibitor of gibberellin biosynthesis, has been studied in many crops to reduce stem elongation in a shaded environment. Its application in tomato plants decreased the seedling height (Seleguini et al. 2013) whereas, in Schizolobium amazonicum, it provided compact seedlings with larger dry root phytomass (Binotti et al. 2019). While the exogenous application of plant growth regulators has not been much explored in shade environments, considerable literature is available regarding their role in the amelioration of drought stress conditions. For example, treating seeds with gibberellic acid improved yield parameters in drought-stressed rapeseed (Brassica napus) (Khan et al. 2020). Exogenously applied gibberellic acid led to improved tolerance in cotton against water deficit stress (Kumar et al. 2001) and Sitka spruce (Picea sitchensis; Philipson 1992). Foliar application of various types of jasmonates enhanced drought tolerance as reported by other reports (Alam et al. 2014, Anjum et al. 2016b, Zheljazkov et al. 2013). Benzyl adenine, an active cytokinin, is documented to potentially enhance the 
drought resistance of different crops (Prerostova et al. 2018). Similarly, exogenous application of 1-aminocyclopropane1-carboxylic acid improved the tolerance against drought stress by hampering the process of ageing (Young et al. 2004), while salicylic acid imparted drought tolerance in wheat by increasing its catalase activity (Horváth et al. 2007). Under co-occurring drought and shade stress, the use of plant growth regulators needs to be explored yet. The possible use of gibberellins and auxin under co-occurring shade and drought stress could be explored as earlier research suggested that application of gibberellins and auxin regulates soybean hypocotyl elongation under co-occurring shade and high-temperature stress (which is usually accompanied by drought stress in most cases) (Bawa et al. 2020).

\section{Application of osmoprotectants}

Asghar et al. (2020) found that a pre-shaded environment enhanced the accumulation of osmoprotectants, such as proline, soluble sugars, and reducing sugars, in soybean seedlings which later enhanced the drought tolerance of the seedlings when exposed to drought stress. This increase is likely because of an increase in abscisic acid contents or an increase in auxin contents in pre-shaded treatment. Similarly, numerous literature has documented an increase in proline (Sperdouli and Moustakas 2012, Cvikrová et al. 2013, Filippou et al. 2014), soluble sugars (Pinheiro and Chaves 2011, Anjum et al. 2017, Du et al. 2020), and glycine betaine (Quan et al. 2004, Zhang et al. 2012) following water deficit stress. Ali et al. (2013) reported that proline applied exogenously under water stress conditions lead to improved composition, oil quality, and oil antioxidant activity of maize seeds. Sakamoto and Murata (2002) reported improved plant growth in drought stress due to foliar-applied glycine betaine as it maintained the leaf water status by improving osmoregulation, $g_{\mathrm{s}}$, and Rubisco activity, which resulted in better photosynthesis. To conclude, it is evident from the above-mentioned literature that osmoprotectants can help impart resistance in plants against shade and drought stress.

\section{Application of mineral nutrients}

The role of mineral nutrients in relieving crops has been widely documented. Wu et al. (2018) found that phosphorous and nitrogen application mitigated negative effects of drought stress on Moso bamboo (Phyllostachys edulis) through enhancing its membrane integrity, wateruse efficiency, and rate of photosynthesis. Phosphorous application in Phoebe zhennan facilitated and improved drought tolerance through physiobiochemical adjustments (Tariq et al. 2017). Zahoor et al. (2017) found that the potassium nutrient management strategy could diminish the effects of drought stress in cotton as its application regulated the translocation process and associated enzyme activities together with the photoassimilation in cotton. The foliar application of $\mathrm{Ca}^{2+}$ was found to be a promising fertilization strategy for the improvement of sugar metabolism, redox state, and the efficiency of mineral nutrients, thereby, enhancing tolerance to water deficit in sugar beet (Beta vulgaris; Hosseini et al. 2019). Sulfate application in form of $\mathrm{K}_{2} \mathrm{SO}_{4}$ mediated drought tolerance in water-stressed maize plants by positively influencing their leaf gas-exchange parameters, leaf water status, and antioxidant mechanism (Usmani et al. 2020). Selenium, though not considered essential for plant growth, improved tolerance to drought in wheat seedlings (Yao et al. 2009) and corn plants (Bocchini et al. 2018). Similarly, silicon, which is the second most abundantly present element in the soil, has not been yet considered an essential plant nutrient mainly due to its poorly understood function in plant biology (Epstein 1994). However, recently, the improvement of crop resistance against water scarcity due to the added silicon in the growth medium has been studied extensively (Hattori et al. 2005, Zhu and Gong 2014, Coskun et al. 2016, Helaly et al. 2017, Thorne et al. 2020). The role of silicon in increasing lodging resistance in shade-grown soybean has also been studied recently. Silicon was found to affect the structural composition of the various components of plant cell walls primarily by changing linkages of noncellulosic polymers and lignin, thus, enhancing lodging resistance and preventing yield losses (Hussain et al. 2020b). Similar to silicon, researchers have looked into the vitality and function that titanium plays in improving crop performance over the last century, but it has not yet been recognized as an essential phytonutrient. Hussain et al. (2019b) reported that a moderate foliar application of ionic titanium enhanced the Chl pigments, biomass production, electron transport rate, and photochemical efficiency of PSII in shade-grown soybean. They suggested that titanium use could help alleviate shade stress, especially in intercropping systems. In conclusion, the above-mentioned data suggest the use of plant mineral nutrients to be a potential source for the achievement of better crop growth and productivity as well as for alleviation of the deleterious impacts of shade and water deficit stress.

\section{Seed priming}

Seed priming is considered one of the most pragmatic approaches to improve the abiotic stress tolerance, especially drought stress, in a range of plant species (Chen and Arora 2013). It involves hydration of the seed to activate the pregerminative metabolic and biochemical activities without radical protrusion during phase two of seed germination (Paparella et al. 2015). This technique can particularly, be very useful for the improvement of rice to be grown in water scant areas, as in the newly introduced aerobic rice culture, the frequency and intensity of drought may increase manifold. Sufficient literature has documented the use of seed-priming treatments for drought resistance in various plant species (Du and Tuong 2002, Harris et al. 2002, Kaur et al. 2005, Kaya et al. 2006, Farooq et al. 2009, Hasanuzzaman and Fujita 2011, Goswami et al. 2013, Samota et al. 2017). However, the effectiveness of priming varies widely depending on the crop species being treated as well as the selected priming technique. Under 
low light conditions, Jiang et al. (2020) found that shadeinduced hypocotyl elongation in soybean is modulated by gibberellins, which are produced in response to the mutual promotion of auxin and brassinosteroid. The use of such plant growth regulators under shade stress can be explored as the above-mentioned evidence suggests a promising role of this technique in conferring drought stress tolerance.

\section{Future perspectives and conclusion}

Shade is a common abiotic stress in crop production and has a serious negative impact on the quality and yield of the crops produced. Unfortunately, although the shade is lethal for crop growth and crops often experience it during their life span (specifically in intercropping systems and highdensity monocropping systems), little attention has been paid to this stress. Plants respond to shade through various complex biochemical, physiological, and molecular mechanisms, together with posttranscriptional regulation via miRNA. Recently, a range of biotechnological tools have been used to better understand the mechanisms by which plants respond to shade stress, nevertheless, these approaches need to be explored further. Modern computational and systems biology tools can be used for recognition of the vital genes, proteins, and metabolites, etc., which could be then utilized for engineering plants that are tolerant to shade. Furthermore, the identification of miRNAs as important regulators of the gene expression under shade stress underscores that miRNA-based biotechnology has great potential for the development of plants that can tolerate shade. Similar to shade, drought stress also has deleterious effects on crop growth. Though, the physiological mechanisms of plants' tolerance against drought have been comparatively described in great detail in the literature, yet we require comprehensive research regarding the responses of roots (involving the root-shoot signalling) under conditions of water scarcity. Moreover, the use of modern era genomic, proteomic, and transcriptomic approaches for a thorough insight of molecular basis of plant's tolerance to drought stress is also imperative. Fundamental knowledge of molecular responses and tolerance mechanisms will help to engineer crops that can withstand drought stress and produce adequate economic yield under such conditions.

Under field conditions, plants encounter multiple stresses simultaneously. Consequently, the occurrence of shade and drought stress simultaneously rather than the occurrence of individual stress, is a major challenge for crop production. Both these stresses alter the growth and development at various growth stages of a plant throughout its life span. The above-reviewed literature provides evidence that plant responses to the co-occurrence of shade and drought stresses may be unique or shared. For example, being unique, shade stress results in stem elongation whereas drought stress results in shorter plant height. In contrast, the consequences of both the stresses include a decrease in flower and pod yield, an increase in flower and pod abortion rate, and a decrease in seed size, all of which leads to a dramatic reduction in seed yield. Although, plant responses to drought and shade stress at morphological and physiological levels, including the structural and biochemical changes, have been well documented at individual leaf and whole-plant levels but what impact does shade has on plant growth under drought conditions, remains unclear. So far, there are no consistent conclusions to date as to whether the interaction of shade and drought stress is antagonistic, synergistic, or additive, as it varies from species to species, the growth period of the plant, and the stress intensity factor. The interactive effect of shade and drought stress is considerably well documented in woody plants and forest species in comparison to the field crops. Therefore, much research is needed on field crop responses to the co-occurrence of shade and drought stress. Proper field experiments should be designed under field conditions to clearly understand the responses. Furthermore, modern-day novel molecular and biotechnological approaches should be used for the development of genetically engineered plants that can respond specifically to shade and drought stress. The use of bioinformatics and genomic sequencing, transcriptomics, and proteomics analysis could further assist in determining shared and unique genes that are regulated under abiotic stress conditions thereby helping improve plants' resistance against individual and concurrent shade and drought stress.

\section{References}

Afzal Z., Howton T.C., Sun Y., Mukhtar M.S.: The roles of aquaporins in plant stress responses. - J. Dev. Biol. 4: 9, 2016.

Ahmed C.B., Rouina B.B., Sensoy S. et al.: Changes in gas exchange, proline accumulation and antioxidative enzyme activities in three olive cultivars under contrasting water availability regimes. - Environ. Exp. Bot. 67: 345-352, 2009.

Alam M.M., Nahar K., Hasanuzzaman M., Fujita M.: Exogenous jasmonic acid modulates the physiology, antioxidant defense and glyoxalase systems in imparting drought stress tolerance in different Brassica species. - Plant Biotechnol. Rep. 8: 279293, 2014.

Ali F., Bano A., Fazal A.: Recent methods of drought stress tolerance in plants. - Plant Growth Regul. 82: 363-375, 2017.

Ali M.B., Hahn E.-J., Paek K.-Y.: Effects of light intensities on antioxidant enzymes and malondialdehyde content during short-term acclimatization on micropropagated Phalaenopsis plantlet. - Environ. Exp. Bot. 54: 109-120, 2005.

Ali Q., Anwar F., Ashraf M. et al.: Ameliorating effects of exogenously applied proline on seed composition, seed oil quality and oil antioxidant activity of maize (Zea mays L.) under drought stress. - Int. J. Mol. Sci. 14: 818-835, 2013.

Amissah L., Mohren G.M., Kyereh B., Poorter L.: The effects of drought and shade on the performance, morphology and physiology of Ghanaian tree species. - PLoS ONE 10: e0121004, 2015.

Anderson J.V., Chevone B.I., Hess J.L.: Seasonal variation in the antioxidant system of eastern white pine needles: evidence for thermal dependence. - Plant Physiol. 98: 501-508, 1992.

Anjum S.A., Ashraf U., Tanveer M. et al.: Drought induced changes in growth, osmolyte accumulation and antioxidant metabolism of three maize hybrids. - Front. Plant Sci. 8: 69, 2017.

Anjum S.A., Tanveer M., Ashraf U. et al.: Effect of progressive drought stress on growth, leaf gas exchange, and antioxidant production in two maize cultivars. - Environ. Sci. Pollut. R. 23: 17132-17141, 2016a. 
Anjum S.A., Tanveer M., Hussain S. et al.: Exogenously applied methyl jasmonate improves the drought tolerance in wheat imposed at early and late developmental stages. - Acta Physiol. Plant. 38: 25, 2016b.

Apel K., Hirt H.: Reactive oxygen species: metabolism, oxidative stress, and signal transduction. - Annu. Rev. Plant Biol. 55: 373-399, 2004

Arenas-Huertero F., Arroyo A., Zhou L. et al:: Analysis of Arabidopsis glucose insensitive mutants, gin5 and gin6, reveals a central role of the plant hormone ABA in the regulation of plant vegetative development by sugar. - Gene. Dev. 14: 2085-2096, 2000.

Asghar M.A., Du J., Jiang H. et al.: Shade pretreatment enhanced drought resistance of soybean. - Environ. Exp. Bot. 171: 103952, 2020

Ashraf M., Harris P.J.C.: Photosynthesis under stressful environments: an overview. - Photosynthetica 51: 163-190, 2013.

Ashraf M., Iram A.: Drought stress induced changes in some organic substances in nodules and other plant parts of two potential legumes differing in salt tolerance. - Flora 200: 535$546,2005$.

Atanasova L., Stefanov D., Yordanov I. et al.: Comparative characteristics of growth and photosynthesis of sun and shade leaves from normal and pendulum walnut (Juglans regia L.) trees. - Photosynthetica 41: 289-292, 2003.

Atlin G.N., Lafitte H.R.: Marker-assisted breeding versus direct selection for drought tolerance in rice. - In: Saxena N.P., O'Toole J.C. (ed.): Field Screening for Drought Tolerance in Crop Plants with Emphasis on Rice: Proceedings of an International Workshop on Field Screening for Drought Tolerance in Rice, 11-14 Dec 2000, ICRISAT, Patancheru, India. Pp. 71-81. ICRISAT, Patancheru, and Rockefeller Foundation, New York 2002.

Badawi G.H., Yamauchi Y., Shimada E. et al.: Enhanced tolerance to salt stress and water deficit by overexpressing superoxide dismutase in tobacco (Nicotiana tabacum) chloroplasts. Plant Sci. 166: 919-928, 2004.

Bahieldin A., Mahfouz H.T., Eissa H.F. et al.: Field evaluation of transgenic wheat plants stably expressing the HVA1 gene for drought tolerance. - Physiol. Plantarum 123: 421-427, 2005.

Baier M., Kandlbinder A., Golldack D., Dietz K.-J.: Oxidative stress and ozone: perception, signalling and response. - Plant Cell Environ. 28: 1012-1020, 2005.

Balouchi H.: Screening wheat parents of mapping population for heat and drought tolerance, detection of wheat genetic variation. - Int. J. Biol. Life Sci 7: 2, 2011.

Barnabás B., Jäger K., Fehér A.: The effect of drought and heat stress on reproductive processes in cereals. - Plant Cell Environ. 31: 11-38, 2008

Bawa G., Feng L., Chen G. et al.: Gibberellins and auxin regulate soybean hypocotyl elongation under low light and hightemperature interaction. - Physiol. Plantarum 170: 345-356, 2020.

Bhargava S., Sawant K.: Drought stress adaptation: metabolic adjustment and regulation of gene expression. - Plant Breeding 132: 21-32, 2013.

Binotti E.D.C., Binotti F.F.S., Lucheti B.Z. et al.: Shading levels and plant growth regulator for formation of Schizolobium amazonicum compact seedlings. - Eng. Agríc. 39: 586-591, 2019.

Blokhina O., Virolainen E., Fagerstedt K.V.: Antioxidants, oxidative damage and oxygen deprivation stress: a review. Ann. Bot.-London 91: 179-194, 2003.

Bocchini M., D'Amato R., Ciancaleoni S. et al.: Soil selenium (Se) biofortification changes the physiological, biochemical and epigenetic responses to water stress in Zea mays L. by inducing a higher drought tolerance. - Front. Plant Sci. 9: 389, 2018.

Boo Y.C., Jung J.: Water deficit-induced oxidative stress and antioxidative defenses in rice plants. - J. Plant Physiol. 155: 255-261, 1999.

Boscaiu M., Fita A.: Physiological and molecular characterization of crop resistance to abiotic stresses. - Agronomy 10: 1308, 2020.

Cagnola J.I., Ploschuk E., Benech-Arnold T. et al:: Stem transcriptome reveals mechanisms to reduce the energetic cost of shade-avoidance responses in tomato. - Plant Physiol. 160: 1110-1119, 2012.

Carneiro I.C.S., Pereira E.G., Souza J.P.: Combined effects of low light and water stress on Jatropha curcas L. promotes shoot growth and morphological adjustment. - Acta Bot. Bras. 29: 467-472, 2015.

Casal J.J.: Shade avoidance. - The Arabidopsis Book 2012: e0157, 2012.

Chandra Babu R., Nguyen B.D., Chamarerk V. et al.: Genetic analysis of drought resistance in rice by molecular markers: association between secondary traits and field performance. Crop Sci. 43: 1457-1469, 2003.

Chandra Babu R., Shashidhar H.E., Lilley J.M. et al.: Variation in root penetration ability, osmotic adjustment and dehydration tolerance among accessions of rice adapted to rainfed lowland and upland ecosystems. - Plant Breeding 120: 233-238, 2001.

Chen B.L., Yang H.K., Ma Y.N. et al:: Effect of shading on yield, fiber quality and physiological characteristics of cotton subtending leaves on different fruiting positions. Photosynthetica 55: 240-250, 2017.

Chen H., Li Q.-P., Zeng Y.-L. et al.: Effect of different shading materials on grain yield and quality of rice. - Sci. Rep.-UK 9: 9992, 2019.

Chen K., Arora R.: Priming memory invokes seed stresstolerance. - Environ. Exp. Bot. 94: 33-45, 2013.

Chen T., Zhang H., Zeng R. et al.: Shade effects on peanut yield associate with physiological and expressional regulation on photosynthesis and sucrose metabolism. - Int. J. Mol. Sci. 21: 5284, 2020.

Chen Z.H., Hills A., Lim C.K., Blatt M.R.: Dynamic regulation of guard cell anion channels by cytosolic free $\mathrm{Ca}^{2+}$ concentration and protein phosphorylation. - Plant J. 61: 816-825, 2010.

Close T.J.: Dehydrins: A commonalty in the response of plants to dehydration and low temperature. - Physiol. Plantarum 100: 291-296, 1997.

Cordero I., Jiménez M.D., Delgado J.A. et al.: Local adaptation optimizes photoprotection strategies in a Neotropical legume tree under drought stress. - Tree Physiol. 41: 1641-1657, 2021.

Coskun D., Britto D.T., Huynh W.Q., Kronzucker H.J.: The role of silicon in higher plants under salinity and drought stress. Front. Plant Sci. 7: 1072, 2016.

Courbier S., Pierik R.: Canopy light quality modulates stress responses in plants. - iScience 22: 441-452, 2019.

Crawford A.J., McLachlan D.H., Hetherington A.M., Franklin K.A.: High temperature exposure increases plant cooling capacity. - Curr. Biol. 22: R396-R397, 2012.

Cruz de Carvalho M.H.: Drought stress and reactive oxygen species: production, scavenging and signaling. - Plant Signal. Behav. 3: 156-165, 2008.

Cui M., Zhang W., Zhang Q. et al.: Induced over-expression of the transcription factor OSDREB2A improves drought tolerance in rice. - Plant Physiol. Bioch. 49: 1384-1391, 2011.

Cvikrová M., Gemperlová L., Martincová O., Vaňková R.: Effect of drought and combined drought and heat stress on polyamine metabolism in proline-over-producing tobacco 
plants. - Plant Physiol. Bioch. 73: 7-15, 2013.

Daryanto S., Wang L., Jacinthe P.-A.: Global synthesis of drought effects on cereal, legume, tuber and root crops production: A review. - Agr. Water Manage. 179: 18-33, 2017.

de Campos M.K.F., de Carvalho K., de Souza F.S. et al.: Drought tolerance and antioxidant enzymatic activity in transgenic 'Swingle'citrumelo plants over-accumulating proline. Environ. Exp. Bot. 72: 242-250, 2011.

Deng F., Wang L., Pu S.-L. et al.: Shading stress increases chalkiness by postponing caryopsis development and disturbing starch characteristics of rice grains. - Agr. Forest Meteorol. 263: 49-58, 2018.

Djakovic-Petrovic T., de Wit M., Voesenek L.A.C.J. et al.: DELLA protein function in growth responses to canopy signals. - Plant J. 51: 117-126, 2007.

Doulis A., Hausladen A., Mondy B. et al.: Antioxidant response and winter hardiness in red spruce (Picea rubens Sarg.). New Phytol. 123: 365-374, 1993.

Du L.V., Tuong T.P.: Enhancing the performance of dry-seeded rice: effects of seed priming, seedling rate, and time of seedling. - In: Pandey S., Mortimer M., Wade L. (ed.): Direct Seeding: Research Strategies and Opportunities. Pp. 241-256. International Research Institute, Manila 2002.

Du Y., Zhao Q., Chen L. et al.: Effect of drought stress on sugar metabolism in leaves and roots of soybean seedlings. - Plant Physiol. Bioch. 146: 1-12, 2020.

Duan J., Cai W.: OsLEA3-2, an abiotic stress induced gene of rice plays a key role in salt and drought tolerance. - PLoS ONE 7: e45117, 2012.

El-Beltagy A.S., Hall M.A.: Effect of water stress upon endogenous ethylene levels in Vicia faba. - New Phytol. 73: 47-60, 1974.

Epstein E.: The anomaly of silicon in plant biology. - P. Natl. Acad. Sci. USA 91: 11-17, 1994.

Ethier G.J., Livingston N.J., Harrison D.L. et al.: Low stomatal and internal conductance to $\mathrm{CO}_{2}$ versus Rubisco deactivation as determinants of the photosynthetic decline of ageing evergreen leaves. - Plant Cell Environ. 29: 2168-2184, 2006.

Fan X.-X., Xu Z.-G., Liu X.-Y. et al.: Effects of light intensity on the growth and leaf development of young tomato plants grown under a combination of red and blue light. - Sci. Hortic.-Amsterdam 153: 50-55, 2013.

Fan Y., Chen J., Cheng Y. et al.: Effect of shading and light recovery on the growth, leaf structure, and photosynthetic performance of soybean in a maize-soybean relay-strip intercropping system. - PLoS ONE 13: e0198159, 2018.

Fang X., Turner N.C., Yan G. et al.: Flower numbers, pod production, pollen viability, and pistil function are reduced and flower and pod abortion increased in chickpea (Cicer arietinum L.) under terminal drought. - J. Exp. Bot. 61: 335$345,2010$.

Farooq M., Nawaz A., Chaudhry M.A.M. et al.: Improving resistance against terminal drought in bread wheat by exogenous application of proline and gamma-aminobutyric acid. - J. Agron. Crop Sci. 203: 464-472, 2017.

Farooq M., Wahid A., Lee D.-J. et al.: Advances in drought resistance of rice. - Crit. Rev. Plant Sci. 28: 199-217, 2009.

Farshadfar E., Ghasempour H., Vaezi H.: Molecular aspects of drought tolerance in bread wheat (T. aestivum). - Pak. J. Biol. Sci. 11: 118-122, 2008.

Feng L., Raza M.A., Chen Y. et al.: Narrow-wide row planting pattern improves the light environment and seed yields of intercrop species in relay intercropping system. - PLoS ONE 14: e0212885, 2019.

Ferroni L., Brestič M., Živčák M. et al.: Increased photosynthesis from a deep-shade to high-light regime occurs by enhanced
$\mathrm{CO}_{2}$ diffusion into the leaf of Selaginella martensii. - Plant Physiol. Bioch. 160: 143-154, 2021.

Filippou P., Bouchagier P., Skotti E. et al.: Proline and reactive oxygen/nitrogen species metabolism is involved in the tolerant response of the invasive plant species Ailanthus altissima to drought and salinity. - Environ. Exp. Bot. 97: 1-10, 2014.

Fiorucci A.-S., Fankhauser C.: Plant strategies for enhancing access to sunlight. - Curr. Biol. 27: R931-R940, 2017.

Fleck I., Peña-Rojas K., Aranda X.: Mesophyll conductance to $\mathrm{CO}_{2}$ and leaf morphological characteristics under drought stress during Quercus ilex L. resprouting. - Ann. For. Sci. 67: 308, 2010.

Fleury D., Jefferies S., Kuchel H., Langridge P.: Genetic and genomic tools to improve drought tolerance in wheat. J. Exp. Bot. 61: 3211-3222, 2010.

Flexas J., Bota J., Cifre J. et al.: Understanding down-regulation of photosynthesis under water stress: future prospects and searching for physiological tools for irrigation management. Ann. Appl. Biol. 144: 273-283, 2004.

Foyer C.H.: Reactive oxygen species, oxidative signaling and the regulation of photosynthesis. - Environ. Exp. Bot. 154: 134142,2018 .

Franklin K.A.: Shade avoidance. - New Phytol. 179: 930-944, 2008.

Frederick J.R., Camp C.R., Bauer P.J.: Drought-stress effects on branch and mainstem seed yield and yield components of determinate soybean. - Crop Sci. 41: 759-763, 2001.

Fujita K., Takagi S., Terashima I.: Leaf angle in Chenopodium album is determined by two processes: induction and cessation of petiole curvature. - Plant Cell Environ. 31: 11381146, 2008.

Furlan A., Llanes A., Luna V. et al.: Physiological and biochemical responses to drought stress and subsequent rehydration in the symbiotic association peanut-Bradyrhizobium sp. - ISRN Agron. 2012: 318083, 2012.

Gallemí M., Galstyan A., Paulišić S. et al.: DRACULA2 is a dynamic nucleoporin with a role in regulating the shade avoidance syndrome in Arabidopsis. - Development 143: 1623-1631, 2016.

Gao J., Shi J., Dong S. et al.: Grain yield and root characteristics of summer maize (Zea mays L.) under shade stress conditions. - J. Agron. Crop Sci. 203: 562-573, 2017.

Gendron J.M., Pruneda-Paz J.L., Doherty C.J. et al.: Arabidopsis circadian clock protein, TOC1, is a DNA-binding transcription factor. - P. Natl. Acad. Sci. USA 109: 3167-3172, 2012.

Genty B., Briantais J.M., Baker N.R.: The relationship between the quantum yield of photosynthetic electron transport and quenching of chlorophyll fluorescence. - BBA-Gen. Subjects 990: 87-92, 1989.

Ghannoum O.: $\mathrm{C}_{4}$ photosynthesis and water stress. - Ann. Bot.London 103: 635-644, 2009.

Ghasemzadeh A., Jaafar H.Z.E., Rahmat A. et al.: Effect of different light intensities on total phenolics and flavonoids synthesis and anti-oxidant activities in young ginger varieties (Zingiber officinale Roscoe). - Int. J. Mol. Sci. 11: 38853897, 2010.

Gommers C.M.M., Visser E.J.W., St Onge K.R. et al.: Shade tolerance: when growing tall is not an option. - Trends Plant Sci. 18: 65-71, 2013.

Gorton H.L., Vogelmann T.C.: Effects of epidermal cell shape and pigmentation on optical properties of Antirrhinum petals at visible and ultraviolet wavelengths. - Plant Physiol. 112: 879-888, 1996.

Goswami A., Banerjee R., Raha S.: Drought resistance in rice seedlings conferred by seed priming: Role of the anti-oxidant defense mechanisms. - Protoplasma 250: 1115-1129, 2013. 
Granier C., Tardieu F.: Leaf expansion and cell division are affected by reducing absorbed light before but not after the decline in cell division rate in the sunflower leaf. - Plant Cell Environ. 22: 1365-1376, 1999.

Green-Tracewicz E., Page E.R., Swanton C.J.: Shade avoidance in soybean reduces branching and increases plant-to-plant variability in biomass and yield per plant. - Weed Sci. 59: 43-49, 2011.

Gundel P.E., Pierik R., Mommer L., Ballaré C.L.: Competing neighbors: light perception and root function. - Oecologia 176: 1-10, 2014

Guo Y.Y., Tian S.S., Liu S.S. et al.: Energy dissipation and antioxidant enzyme system protect photosystem II of sweet sorghum under drought stress. - Photosynthetica 56: 861-872, 2018.

Gupta N., Thind S.K., Bains N.S.: Glycine betaine application modifies biochemical attributes of osmotic adjustment in drought stressed wheat. - Plant Growth Regul. 72: 221-228, 2014.

Gupta P.K., Balyan H.S., Gahlaut V.: QTL analysis for drought tolerance in wheat: present status and future possibilities. Agronomy 7: 5, 2017.

Harris D., Tripathi R.S, Joshi A.: On-farm seed priming to improve crop establishment and yield in dry direct-seeded rice. - In: Pandey S., Mortimer M., Wade L. (ed.): Direct Seeding: Research Strategies and Opportunities. Pp. 231-240. International Research Institute, Manila 2002.

Hasanuzzaman M., Fujita M.: Selenium pretreatment upregulates the antioxidant defense and methylglyoxal detoxification system and confers enhanced tolerance to drought stress in rapeseed seedlings. - Biol. Trace Elem. Res. 143: 1758-1776, 2011.

Hattori T., Inanaga S., Araki H. et al.: Application of silicon enhanced drought tolerance in Sorghum bicolor. - Physiol. Plantarum 123: 459-466, 2005.

Havlin J.L., Tisdale S.L., Nelson W.L., Beaton J.D.: Soil Fertility and Fertilizers: An Introduction to Nutrient Management. $8^{\text {th }}$ Edition. Pp. 529. Pearson India, 2016.

He J.X., Wang J., Liang H.G.: Effects of water stress on photochemical function and protein metabolism of photosystem II in wheat leaves. - Physiol. Plantarum 93: 771-777, 1995.

Hébert Y., Guingo E., Loudet O.: The response of root/shoot partitioning and root morphology to light reduction in maize genotypes. - Crop Sci. 41: 363-371, 2001.

Helaly M.N., El-Hoseiny H., El-Sheery N.I. et al.: Regulation and physiological role of silicon in alleviating drought stress of mango. - Plant Physiol. Bioch. 118: 31-44, 2017.

Holmgren M., Scheffer M., Huston M.A.: The interplay of facilitation and competition in plant communities. - Ecology 78: 1966-1975, 1997.

Holmgren M.: Combined effects of shade and drought on tulip poplar seedlings: trade-off in tolerance or facilitation? Oikos 90: 67-78, 2000.

Horváth E., Pál M., Szalai G. et al.: Exogenous 4-hydroxybenzoic acid and salicylic acid modulate the effect of short-term drought and freezing stress on wheat plants. - Biol. Plantarum 51: 480-487, 2007

Hossain A., Skalicky M., Brestic M. et al.: Consequences and mitigation strategies of abiotic stresses in wheat (Triticum aestivum L.) under the changing climate. - Agronomy 11: 241, 2021.

Hosseini S.A., Réthoré E., Pluchon S. et al.: Calcium application enhances drought stress tolerance in sugar beet and promotes plant biomass and beetroot sucrose concentration. - Int. J. Mol. Sci. 20: 3777, 2019.
Hu Y., Schmidhalter U.: Drought and salinity: a comparison of their effects on mineral nutrition of plants. - J. Soil Sci. Plant Nutr. 168: 541-549, 2005.

Huber H., Kane N.C., Heschel M.S. et al.: Frequency and microenvironmental pattern of selection on plastic shadeavoidance traits in a natural population of Impatiens capensis. - Am. Nat. 163: 548-563, 2004.

Hussain H.A., Men S., Hussain S. et al.: Interactive effects of drought and heat stresses on morpho-physiological attributes, yield, nutrient uptake and oxidative status in maize hybrids. Sci. Rep.-UK 9: 3890, 2019c.

Hussain S., Iqbal N., Brestic M. et al.: Changes in morphology, chlorophyll fluorescence performance and Rubisco activity of soybean in response to foliar application of ionic titanium under normal light and shade environment. - Sci. Total Environ. 658: 626-637, 2019b.

Hussain S., Iqbal N., Rahman T. et al.: Shade effect on carbohydrates dynamics and stem strength of soybean genotypes. - Environ. Exp. Bot. 162: 374-382, 2019 a.

Hussain S., Li S.X., Mumtaz M. et al.: Foliar application of silicon improves stem strength under low light stress by regulating lignin biosynthesis genes in soybean (Glycine max (L.) Merr.). - J. Hazard. Mater. 401: 123256, 2020 b.

Hussain S., Liu T., Iqbal N. et al.: Effects of lignin, cellulose, hemicellulose, sucrose and monosaccharide carbohydrates on soybean physical stem strength and yield in intercropping. Photoch. Photobio. Sci. 19: 462-472, 2020a.

Iqbal N., Hussain S., Raza M.A. et al.: Drought tolerance of soybean (Glycine max L. Merr.) by improved photosynthetic characteristics and an efficient antioxidant enzyme system under a split-root system. - Front. Physiol. 10: 786, 2019.

Jaleel C.A., Gopi R., Sankar B. et al.: Differential responses in water use efficiency in two varieties of Catharanthus roseus under drought stress. - C. R. Biol. 331: 42-47, 2008.

Jiang H., Shui Z., Xu L. et al.: Gibberellins modulate shadeinduced soybean hypocotyl elongation downstream of the mutual promotion of auxin and brassinosteroids. - Plant Physiol. Bioch. 150: 209-221, 2020.

Jongdee B., Fukai S., Cooper M.: Leaf water potential and osmotic adjustment as physiological traits to improve drought tolerance in rice. - Field Crop. Res. 76: 153-163, 2002.

Joo J.H., Bae Y.S., Lee J.S.: Role of auxin-induced reactive oxygen species in root gravitropism. - Plant Physiol. 126: 1055-1060, 2001.

Kamara A.Y., Menkir A., Badu-Apraku B., Ibikunle O.: The influence of drought stress on growth, yield and yield components of selected maize genotypes. - J. Agr. Sci. 141: 43-50, 2003.

Kamiya Y., García-Martínez J.L.: Regulation of gibberellin biosynthesis by light. - Curr. Opin. Plant Biol. 2: 398-403, 1999.

Karabourniotis G., Liakopoulos G., Bresta P., Nikolopoulos D.: The optical properties of leaf structural elements and their contribution to photosynthetic performance and photoprotection. - Plants-Basel 10: 1455, 2021.

Kashiwagi J., Krishnamurthy L., Purushothaman R. et al.: Scope for improvement of yield under drought through the root traits in chickpea (Cicer arietinum L.). - Field Crop. Res. 170: 4754, 2015.

Kaur G., Asthir B.: Molecular responses to drought stress in plants. - Biol. Plantarum 61: 201-209, 2017.

Kaur S., Gupta A.K., Kaur N.: Seed priming increases crop yield possibly by modulating enzymes of sucrose metabolism in chickpea. - J. Agron. Crop Sci. 191: 81-87, 2005.

Kaya M.D., Okçu G., Atak M. et al.: Seed treatments to overcome salt and drought stress during germination in sunflower 
(Helianthus annuus L.). - Eur. J. Agron. 24: 291-295, 2006.

Keleş Y., Öncel I.: Response of antioxidative defence system to temperature and water stress combinations in wheat seedlings. - Plant Sci. 163: 783-790, 2002.

Keuskamp D.H., Sasidharan R., Pierik R.: Physiological regulation and functional significance of shade avoidance responses to neighbors. - Plant Signal. Behav. 5: 655-662, 2010.

Khan M.N., Khan Z., Luo T. et al.: Seed priming with gibberellic acid and melatonin in rapeseed: Consequences for improving yield and seed quality under drought and non-stress conditions. - Ind. Crop. Prod. 156: 112850, 2020.

Knapp A.K., Smith W.K.: Stomatal and photosynthetic responses to variable sunlight. - Physiol. Plantarum 78: 160-165, 1990.

Kolb T.E., Steiner K.C., McCormick L.H., Bowersox T.W.: Growth response of northern red-oak and yellow-poplar seedlings to light, soil moisture and nutrients in relation to ecological strategy. - Forest Ecol. Manag. 38: 65-78, 1990.

Kozuka T., Horiguchi G., Kim G.-T. et al.: The different growth responses of the Arabidopsis thaliana leaf blade and the petiole during shade avoidance are regulated by photoreceptors and sugar. - Plant Cell Physiol. 46: 213-223, 2005.

Kozuka T., Kobayashi J., Horiguchi G. et al.: Involvement of auxin and brassinosteroid in the regulation of petiole elongation under the shade. - Plant Physiol. 153: 1608-1618, 2010 .

Kubiske M.E., Abrams M.D., Mostoller S.A.: Stomatal and nonstomatal limitations of photosynthesis in relation to the drought and shade tolerance of tree species in open and understory environments. - Trees 11: 76-82, 1996.

Kuchenbuch R., Claassen N., Jungk A.: Potassium availability in relation to soil moisture. - Plant Soil 95: 233-243, 1986.

Kumar B., Pandey D.M., Goswami C.L., Jain S.: Effect of growth regulators on photosynthesis, transpiration and related parameters in water stressed cotton. - Biol. Plantarum 44: 475-478, 2001.

Lanceras J.C., Pantuwan G., Jongdee B. et al.: Quantitative trait loci associated with drought tolerance at reproductive stage in rice. - Plant Physiol. 135: 384-399, 2004.

Lawlor D.W., Tezara W.: Causes of decreased photosynthetic rate and metabolic capacity in water-deficient leaf cells: a critical evaluation of mechanisms and integration of processes. Ann. Bot.-London 103: 561-579, 2009.

Leong T.Y., Anderson J.M.: Adaptation of the thylakoid membranes of pea chloroplasts to light intensities. I. Study on the distribution of chlorophyll-protein complexes. Photosynth. Res. 5: 105-115, 1984.

Li H., Jiang D., Wollenweber B. et al.: Effects of shading on morphology, physiology and grain yield of winter wheat. Eur. J. Agron. 33: 267-275, 2010.

Li J., Besseau S., Törönen P. et al.: Defense-related transcription factors WRKY70 and WRKY54 modulate osmotic stress tolerance by regulating stomatal aperture in Arabidopsis. New Phytol. 200: 457-472, 2013.

Li W., Katin-Grazzini L., Gu X. et al.: Transcriptome analysis reveals differential gene expression and a possible role of gibberellins in a shade-tolerant mutant of perennial ryegrass. Front. Plant Sci. 8: 868, 2017.

Liakoura V., Stefanou M., Manetas Y. et al.: Trichome density and its UV-B protective potential are affected by shading and leaf position on the canopy. - Environ. Exp. Bot. 38: 223-229, 1997.

Liu F., Jensen C.R., Andersen M.N.: Drought stress effect on carbohydrate concentration in soybean leaves and pods during early reproductive development: its implication in altering pod set. - Field Crop. Res. 86: 1-13, 2004.
Liu J., Hu B., Liu W. et al.: Metabolomic tool to identify soybean [Glycine $\max (\mathrm{L}$.$) Merrill] germplasms with a high level$ of shade tolerance at the seedling stage. - Sci. Rep.-UK 7: 42478, 2017.

Liu Q.-H., Xiu W., Chen B.-C. et al.: Effects of low light on agronomic and physiological characteristics of rice including grain yield and quality. - Rice Sci. 21: 243-251, 2014.

Liu Y., Wei H., Ma M. et al.: Arabidopsis FHY3 and FAR1 regulate the balance between growth and defense responses under shade conditions. - Plant Cell 31: 2089-2106, 2019.

Lombardini L., Restrepo-Diaz H., Volder A.: Photosynthetic light response and epidermal characteristics of sun and shade pecan leaves. - J. Am. Soc. Hortic. Sci. 134: 372-378, 2009.

López-Calcagno P.E., Howard T.P., Raines C.A.: The CP12 protein family: a thioredoxin-mediated metabolic switch? Front. Plant Sci. 5: 9, 2014.

Ludlow M.M., Muchow R.C.: A critical evaluation of traits for improving crop yields in water-limited environments. - Adv. Agron. 43: 107-153, 1990.

Ma D., Sun D., Wang C. et al.: Expression of flavonoid biosynthesis genes and accumulation of flavonoid in wheat leaves in response to drought stress. - Plant Physiol. Bioch. 80: 60-66, 2014.

Mahajan S., Tuteja N.: Cold, salinity and drought stresses: an overview. - Arch. Biochem. Biophys. 444: 139-158, 2005.

Maitra S., Hossain A., Brestic M. et al.: Intercropping a low input agricultural strategy for food and environmental security. - Agronomy 11: 343, 2021.

Manivannan P., Jaleel C.A., Sankar B. et al.: Growth, biochemical modifications and proline metabolism in Helianthus annuus L. as induced by drought stress. - Colloid. Surface. B 59: 141149, 2007.

Manschadi A.M., Christopher J., deVoil P., Hammer G.L.: The role of root architectural traits in adaptation of wheat to waterlimited environments. - Funct. Plant Biol. 33: 823-837, 2006.

Maqbool M.A., Aslam M., Ali H.: Breeding for improved drought tolerance in chickpea (Cicer arietinum L.). - Plant Breeding 136: 300-318, 2017.

Marshall J.D.: Drought and shade interact to cause fine-root mortality in Douglas-fir seedlings. - Plant Soil 91: 51-60, 1986.

McCourt P., Creelman R.: The ABA receptors - we report you decide. - Curr. Opin. Plant Biol. 11: 474-478, 2008.

Melis A.: Dynamics of photosynthetic membrane composition and function. - BBA-Bioenergetics 1058: 87-106, 1991.

Mishio M., Kawakubo N.: Variations in leaf morpho-anatomy and photosynthetic traits between sun and shade populations of Eurya japonica (Pentaphylacaceae) whose seeds are dispersed by birds across habitats. - Plant Spec. Biol. 30: 147-158, 2015.

Mittler R., Blumwald E.: The roles of ROS and ABA in systemic acquired acclimation. - Plant Cell 27: 64-70, 2015.

Mohammad S., Khan M.A., Ali A. et al.: Feasible production of biomass and natural antioxidants through callus cultures in response to varying light intensities in olive (Olea europaea L.) cult. Arbosana. - J. Photoch. Photobio. B 193: 140-147, 2019.

Murchie E., Hubbart S., Peng S., Horton P.: Acclimation of photosynthesis to high irradiance in rice: gene expression and interactions with leaf development. - J. Exp. Bot. 56: 449460, 2005.

Mustilli A.-C., Merlot S., Vavasseur A. et al.: Arabidopsis OST1 protein kinase mediates the regulation of stomatal aperture by abscisic acid and acts upstream of reactive oxygen species production. - Plant Cell 14: 3089-3099, 2002.

Nakashima K., Yamaguchi-Shinozaki K., Shinozaki K.: The 
transcriptional regulatory network in the drought response and its crosstalk in abiotic stress responses including drought, cold, and heat. - Front. Plant Sci. 5: 170, 2014.

Nayyar H., Gupta D.: Differential sensitivity of $\mathrm{C}_{3}$ and $\mathrm{C}_{4}$ plants to water deficit stress: association with oxidative stress and antioxidants. - Environ. Exp. Bot. 58: 106-113, 2006.

Nir I., Shohat H., Panizel I. et al.: The tomato DELLA protein PROCERA acts in guard cells to promote stomatal closure. Plant Cell 29: 3186-3197, 2017.

Noctor G., Veljovic-Jovanovic S., Driscoll S. et al.: Drought and oxidative load in the leaves of $\mathrm{C}_{3}$ plants: a predominant role for photorespiration? - Ann. Bot.-London 89: 841-850, 2002.

Olsovska K., Kovar M., Brestic M. et al.: Genotypically identifying wheat mesophyll conductance regulation under progressive drought stress. - Front. Plant Sci. 7: 1111, 2016.

Oneto C.D., Otegui M.E., Baroli I. et al.: Water deficit stress tolerance in maize conferred by expression of an isopentenyltransferase (IPT) gene driven by a stress-and maturation-induced promoter. - J. Biotechnol. 220: 66-77, 2016.

Ouk M., Basnayake J., Tsubo M. et al.: Use of drought response index for identification of drought tolerant genotypes in rainfed lowland rice. - Field Crop. Res. 99: 48-58, 2006.

Paparella S., Araújo S.S., Rossi G. et al.: Seed priming: state of the art and new perspectives. - Plant Cell Rep. 34: 1281-1293, 2015.

Pardos M., Calama R.: Responses of Pinus pinea seedlings to moderate drought and shade: is the provenance a differential factor? - Photosynthetica 56: 786-798, 2018.

Paredes P., de Melo-Abreu J.P., Alves I., Pereira L.S.: Assessing the performance of the FAO AquaCrop model to estimate maize yields and water use under full and deficit irrigation with focus on model parameterization. - Agr. Water Manage. 144: 81-97, 2014.

Park S.-Y., Grabau E.: Bypassing miRNA-mediated gene regulation under drought stress: alternative splicing affects CSD1 gene expression. - Plant Mol. Biol. 95: 243-252, 2017.

Pei Z.M., Murata Y., Benning G. et al.: Calcium channels activated by hydrogen peroxide mediate abscisic acid signalling in guard cells. - Nature 406: 731-734, 2000.

Pereyra-Irujo G.A., Velázquez L., Lechner L., Aguirrezábal L.A.N.: Genetic variability for leaf growth rate and duration under water deficit in sunflower: analysis of responses at cell, organ, and plant level. - J. Exp. Bot. 59: 2221-2232, 2008.

Pettigrew W.T.: Physiological consequences of moisture deficit stress in cotton. - Crop Sci. 44: 1265-1272, 2004.

Philipson J.J.: Optimal conditions for inducing coning of container-grown Picea sitchensis grafts: effects of applying different quantities of GA4/7, timing and duration of heat and drought treatment, and girdling. - Forest Ecol. Manag. 53: 39-52, 1992

Pinheiro C., Chaves M.M.: Photosynthesis and drought: can we make metabolic connections from available data? - J. Exp. Bot. 62: 869-882, 2011.

Polle A., Rennenberg H.: Field studies on Norway spruce trees at high altitudes: II. Defence systems against oxidative stress in needles. - New Phytol. 121: 635-642, 1992.

Pons T.L., Jordi W., Kuiper D.: Acclimation of plants to light gradients in leaf canopies: evidence for a possible role for cytokinins transported in the transpiration stream. - J. Exp. Bot. 52: 1563-1574, 2001

Prashanth S., Sadhasivam V., Parida A.: Over expression of cytosolic copper/zinc superoxide dismutase from a mangrove plant Avicennia marina in indica rice var Pusa Basmati-1 confers abiotic stress tolerance. - Transgenic Res. 17: 281291,2008 .
Prerostova S., Dobrev P.I., Gaudinova A. et al.: Cytokinins: Their impact on molecular and growth responses to drought stress and recovery in Arabidopsis. - Front. Plant Sci. 9: 655, 2018.

Quan R., Shang M., Zhang H. et al.: Engineering of enhanced glycine betaine synthesis improves drought tolerance in maize. - Plant Biotechnol. J. 2: 477-486, 2004.

Rahman H., Pekic S., Lazic-Jancic V. et al.: Molecular mapping of quantitative trait loci for drought tolerance in maize plants. - Genet. Mol. Res. 10: 889-901, 2011.

Rahman T., Liu X., Hussain S. et al.: Water use efficiency and evapotranspiration in maize-soybean relay strip intercrop systems as affected by planting geometries. - PLoS ONE 12: e0178332, 2017a.

Rahman T., Ye L., Liu X. et al.: Water use efficiency and water distribution response to different planting patterns in maizesoybean relay strip intercropping systems. - Exp. Agr. 53: 159-177, 2017b.

Ranade S.S., Delhomme N., García-Gil M.R.: Transcriptome analysis of shade avoidance and shade tolerance in conifers. Planta 250: 299-318, 2019.

Ratnayaka H.H., Molin W.T., Sterling T.M.: Physiological and antioxidant responses of cotton and spurred anoda under interference and mild drought. - J. Exp. Bot. 54: 2293-2305, 2003.

Ray S., Mondal W.A., Choudhuri M.A.: Regulation of leaf senescence, grain-filling and yield of rice by kinetin and abscisic acid. - Physiol. Plantarum 59: 343-346, 1983.

Raza M.A., Feng L.Y., van der Werf W. et al.: Narrow-widerow planting pattern increases the radiation use efficiency and seed yield of intercrop species in relay-intercropping system. - Food Energ. Secur. 8: e170, 2019a.

Raza M.A., Khalid M.H.B., Zhang X. et al.: Effect of planting patterns on yield, nutrient accumulation and distribution in maize and soybean under relay intercropping systems. - Sci. Rep.-UK 9: 4947, 2019b.

Reddy A.R., Chaitanya K.V., Vivekanandan M.: Drought-induced responses of photosynthesis and antioxidant metabolism in higher plants. - J. Plant Physiol. 161: 1189-1202, 2004.

Roig-Villanova I., Martínez-García J.F.: Plant responses to vegetation proximity: a whole life avoiding shade. - Front. Plant Sci. 7: 236, 2016.

Runion G.B, Mitchell R.J., Rogers H.H. et al.: Effects of nitrogen and water limitation and elevated atmospheric $\mathrm{CO}_{2}$ on ectomycorrhiza of longleaf pine. - New Phytol. 137: 681-689, 1997.

Sack L.: Responses of temperate woody seedlings to shade and drought: do trade-offs limit potential niche differentiation? Oikos 107: 110-127, 2004.

Sack L., Grubb P.J.: The combined impacts of deep shade and drought on the growth and biomass allocation of shadetolerant woody seedlings. - Oecologia 131: 175-185, 2002.

Sakamoto A., Murata N.: The role of glycine betaine in the protection of plants from stress: clues from transgenic plants. - Plant Cell Environ. 25: 163-171, 2002.

Salter M.G., Franklin K.A., Whitelam G.C.: Gating of the rapid shade-avoidance response by the circadian clock in plants. Nature 426: 680-683, 2003.

Samota M.K., Sasi M., Awana M. et al.: Elicitor-induced biochemical and molecular manifestations to improve drought tolerance in rice (Oryza sativa L.) through seed-priming. Front. Plant Sci. 8: 934, 2017.

Sanders D., Brownlee C., Harper J.F.: Communicating with calcium. - Plant Cell 11: 691-706, 1999.

Sanders D., Pelloux J., Brownlee C., Harper J.F.: Calcium at the crossroads of signaling. - Plant Cell 14: S401-S417, 2002.

Schachtman D.P., Goodger J.Q.: Chemical root to shoot signaling 
under drought. - Trends Plant Sci. 13: 281-287, 2008.

Scippa G.S., Di Michele M., Onelli E. et al.: The histone-like protein H1-S and the response of tomato leaves to water deficit. - J. Exp. Bot. 55: 99-109, 2004.

Seki M., Narusaka M., Abe H. et al.: Monitoring the expression pattern of 1300 Arabidopsis genes under drought and cold stresses by using a full-length cDNA microarray. - Plant Cell 13: 61-72, 2001 .

Seleguini A., De Araujo Faria Júnior M.J., Benett K.S.S. et al.: Strategies for tomato seedlings production using paclobutrazol. - Semina Ciên. Agrár. 34: 539-548, 2013.

Sgherri C.L.M., Pinzino C., Navari-Izzo F.: Chemical changes and $\mathrm{O}_{2}^{-}$production in thylakoid membranes under water stress. - Physiol. Plantarum 87: 211-216, 1993.

Shafiq I., Hussain S., Hassan B. et al.: Effect of simultaneous shade and drought stress on morphology, leaf gas exchange, and yield parameters of different soybean cultivars. Photosynthetica 58: 1200-1209, 2020.

Shafiq I., Hussain S., Raza M.A. et al.: Crop photosynthetic response to light quality and light intensity. - J. Integr. Agr. 20: 4-23, 2021.

Sharma P., Dubey R.S.: Drought induces oxidative stress and enhances the activities of antioxidant enzymes in growing rice seedlings. - Plant Growth Regul. 46: 209-221, 2005.

Shi G., Xia S., Ye J. et al.: PEG-simulated drought stress decreases cadmium accumulation in castor bean by altering root morphology. - Environ. Exp. Bot. 111: 127-134, 2015.

Siddique M.R.B., Hamid A., Islam M.S.: Drought stress effects on water relations of wheat. - Bot. Bull. Acad. Sin 41: 35-39, 2000.

Simon-Sarkadi L., Kocsy G., Várhegyi Á. et al.: Stress-induced changes in the free amino acid composition in transgenic soybean plants having increased proline content. - Biol. Plantarum 50: 793-796, 2006.

Sinclair T.R., Sheehy J.E.: Erect leaves and photosynthesis in rice. - Science 283: 1456-1456, 1999.

Sivamani E., Bahieldin A., Wraith J.M. et al.: Improved biomass productivity and water use efficiency under water deficit conditions in transgenic wheat constitutively expressing the barley HVA1 gene. - Plant Sci. 155: 1-9, 2000.

Skirycz A., De Bodt S., Obata T. et al.: Developmental stage specificity and the role of mitochondrial metabolism in the response of Arabidopsis leaves to prolonged mild osmotic stress. - Plant Physiol. 152: 226-244, 2010.

Smith T., Huston M.: A theory of the spatial and temporal dynamics of plant communities. - In: Grabherr G., Mucina L., Dale M.B., Ter Braak C.J.F. (ed.): Progress in Theoretical Vegetation Science. Advances in Vegetation Science. Vol. 11. Pp. 49-69. Springer, Dordrecht 1990.

Soltys-Kalina D., Plich J., Strzelczyk-Żyta D. et al.: The effect of drought stress on the leaf relative water content and tuber yield of a half-sib family of 'Katahdin'-derived potato cultivars. Breeding Sci. 66: 328-331, 2016.

Sperdouli I., Moustakas M.: Interaction of proline, sugars, and anthocyanins during photosynthetic acclimation of Arabidopsis thaliana to drought stress. - J. Plant Physiol. 169: 577-585, 2012.

Sun J., Hu W., Zhou R. et al.: The Brachypodium distachyon BdWRKY36 gene confers tolerance to drought stress in transgenic tobacco plants. - Plant Cell Rep. 34: 23-35, 2015.

Suriyagoda L., De Costa W.A.J.M., Lambers H.: Growth and phosphorus nutrition of rice when inorganic fertiliser application is partly replaced by straw under varying moisture availability in sandy and clay soils. - Plant Soil 384: 53-68, 2014.

Tahir M.H.N., Imran M., Hussain M.K.: Evaluation of sunflower
(Helianthus annuus L.) inbred lines for drought tolerance. Int. J. Agric. Biol. 3: 398-400, 2002.

Tan T., Li S., Fan Y. et al.: Far-red light: a regulator of plant morphology and photosynthetic capacity. - Crop J., 2021. (In press)

Tariq A., Pan K., Olatunji O.A. et al.: Phosphorous application improves drought tolerance of Phoebe zhennan. - Front. Plant Sci. 8: 1561, 2017.

Tegg R.S., Lane P.A.: Shade adaptation of established turfgrass improved by plant growth regulator. - In: Science and Technology: Delivering Results for Agriculture? Proceedings of the $10^{\text {th }}$ Australian Agronomy Conference, 29 January1 February 2001, Hobart, Tasmania, 2001.

Terashima I., Miyazawa S.I., Hanba Y.T.: Why are sun leaves thicker than shade leaves? - Consideration based on analyses of $\mathrm{CO}_{2}$ diffusion in the leaf. - J. Plant Res. 114: 93-105, 2001.

Thorne S.J., Hartley S.E., Maathuis F.J.M.: Is silicon a panacea for alleviating drought and salt stress in crops? - Front. Plant Sci. 11: 1221, 2020.

Türkan I., Bor M., Özdemir F., Koca H.: Differential responses of lipid peroxidation and antioxidants in the leaves of droughttolerant $P$. acutifolius Gray and drought-sensitive $P$. vulgaris L. subjected to polyethylene glycol mediated water stress. Plant Sci. 168: 223-231, 2005.

Usmani M.M., Nawaz F., Majeed S. et al.: Sulfate-mediated drought tolerance in maize involves regulation at physiological and biochemical levels. - Sci. Rep.-UK 10: 1147, 2020.

Valladares F., Niinemets Ü.: Shade tolerance, a key plant feature of complex nature and consequences. - Annu. Rev. Ecol. Evol. S. 39: 237-257, 2008.

van Gelderen K., Kang C., Paalman R. et al.: Far-red light detection in the shoot regulates lateral root development through the HY5 transcription factor. - Plant Cell 30: 101$116,2018 b$.

van Gelderen K., Kang C., Pierik R.: Light signaling, root development, and plasticity. - Plant Physiol. 176: 1049-1060, 2018a.

Vance N.C., Zaerr J.B.: Influence of drought stress and low irradiance on plant water relations and structural constituents in needles of Pinus ponderosa seedlings. - Tree Physiol. 8: 175-184, 1991.

Varshney R.K., Kudapa H., Roorkiwal M. et al.: Advances in genetics and molecular breeding of three legume crops of semi-arid tropics using next-generation sequencing and highthroughput genotyping technologies. - J. Biosci. 37: 811-820, 2012.

Vasantha S., Alarmelu S., Hemaprabha G., Shanthi R.M.: Evaluation of promising sugarcane genotypes for drought. Sugar Tech. 7: 82-83, 2005.

Vendruscolo E.C.G., Schuster I., Pileggi M. et al.: Stress-induced synthesis of proline confers tolerance to water deficit in transgenic wheat. - J. Plant Physiol. 164: 1367-1376, 2007.

Verhoeven A.S., Swanberg A., Thao M., Whiteman J.: Seasonal changes in leaf antioxidant systems and xanthophyll cycle characteristics in Taxus $\times$ media growing in sun and shade environments. - Physiol. Plantarum 123: 428-434, 2005.

Verulkar S.B., Mandal N.P., Dwivedi J.L. et al.: Breeding resilient and productive genotypes adapted to drought-prone rainfed ecosystem of India. - Field Crop. Res. 117: 197-208, 2010.

Volkov R.A., Panchuk I.I., Mullineaux P.M., Schöffl F.: Heat stress-induced $\mathrm{H}_{2} \mathrm{O}_{2}$ is required for effective expression of heat shock genes in Arabidopsis. - Plant Mol. Biol. 61: 733746, 2006.

Wang X., Roig-Villanova I., Khan S. et al:: A novel highthroughput in vivo molecular screen for shade avoidance mutants identifies a novel phyA mutation. - J. Exp. Bot. 62: 
2973-2987, 2011.

Warren C.R.: Does growth temperature affect the temperature responses of photosynthesis and internal conductance to $\mathrm{CO}_{2}$ ? A test with Eucalyptus regnans. - Tree Physiol. 28: 11-19, 2008.

Wen B., Zhang Y., Hussain S. et al.: Slight shading stress at seedling stage does not reduce lignin biosynthesis or affect lodging resistance of soybean stems. - Agronomy 10: 544, 2020.

Werker E.: Trichome diversity and development. - Adv. Bot. Res. 31: 1-35, 2000.

Wu D., Li L., Ma X. et al.: Morphological and anatomical adaptations to dry, shady environments in Adiantum reniforme var. sinense (Pteridaceae). - PeerJ 8: e9937, 2020.

X., Shiroto Y., Kishitani S. et al.: Enhanced heat and drought tolerance in transgenic rice seedlings overexpressing OsWRKY11 under the control of HSP101 promoter. - Plant Cell Rep. 28: 21-30, 2009.

Wu Y., Gong W., Yang W.: Shade inhibits leaf size by controlling cell proliferation and enlargement in soybean. - Sci. Rep.-UK 7: 9259, 2017

Wu Z.Z., Ying Y.Q., Zhang Y.B. et al.: Alleviation of drought stress in Phyllostachys edulis by $\mathrm{N}$ and $\mathrm{P}$ application. - Sci. Rep.-UK 8: 228, 2018.

Xiao B., Huang Y., Tang N., Xiong L.: Over-expression of a LEA gene in rice improves drought resistance under the field conditions. - Theor. Appl. Genet. 115: 35-46, 2007.

Xiong L., Wang R.-G., Mao G., Koczan J.M.: Identification of drought tolerance determinants by genetic analysis of root response to drought stress and abscisic acid. - Plant Physiol. 142: 1065-1074, 2006.

Xu D., Duan X., Wang B. et al.: Expression of a late embryogenesis abundant protein gene, HVA1, from barley confers tolerance to water deficit and salt stress in transgenic rice. - Plant Physiol. 110: 249-257, 1996.

Yamada M., Morishita H., Urano K. et al.: Effects of free proline accumulation in petunias under drought stress. - J. Exp. Bot. 56: 1975-1981, 2005.

Yan J., Wang J., Tissue D. et al.: Photosynthesis and seed production under water-deficit conditions in transgenic tobacco plants that overexpress an Arabidopsis ascorbate peroxidase gene. - Crop Sci. 43: 1477-1483, 2003.

Yang F., Huang S., Gao R. et al.: Growth of soybean seedlings in relay strip intercropping systems in relation to light quantity and red:far-red ratio. - Field Crop. Res. 155: 245-253, 2014.

Yang F., Liao D., Wu X. et al.: Effect of aboveground and belowground interactions on the intercrop yields in maizesoybean relay intercropping systems. - Field Crop. Res. 203: 16-23, 2017.

Yang F., Miao L.-F.: Adaptive responses to progressive drought stress in two poplar species originating from different altitudes. - Silva Fenn. 44: 23-37, 2010.

Yang S., Vanderbeld B., Wan J., Huang Y.: Narrowing down the targets: towards successful genetic engineering of droughttolerant crops. - Mol. Plant 3: 469-490, 2010.

Yano S., Terashima I.: Developmental process of sun and shade leaves in Chenopodium album L. - Plant Cell Environ. 27: 781-793, 2004.

Yao X., Chu J., Wang G.: Effects of selenium on wheat seedlings under drought stress. - Biol. Trace Elem. Res. 130: 283-290, 2009.

Young T.E., Meeley R.B., Gallie D.R.: ACC synthase expression regulates leaf performance and drought tolerance in maize. Plant J. 40: 813-825, 2004.

Yuan L., Tang J., Wang X., Li C.: QTL analysis of shading sensitive related traits in maize under two shading treatments. PLoS ONE 7: e38696, 2012.

Zahoor R., Dong H., Abid M. et al.: Potassium fertilizer improves drought stress alleviation potential in cotton by enhancing photosynthesis and carbohydrate metabolism. - Environ. Exp. Bot. 137: 73-83, 2017.

Zhang J., Smith D.L., Liu W. et al.: Effects of shade and drought stress on soybean hormones and yield of main-stem and branch. - Afr. J. Biotechnol. 10: 14392-14398, 2011.

Zhang L., Gao M., Hu J. et al.: Modulation role of abscisic acid (ABA) on growth, water relations and glycinebetaine metabolism in two maize (Zea mays L.) cultivars under drought stress. - Int. J. Mol. Sci. 13: 3189-3202, 2012.

Zheljazkov V.D., Astatkie T., Jeliazkova E.: Effect of foliar application of methyl jasmonate and extracts of juniper and sagebrush on essential oil yield and composition of 'Native'spearmint. - HortScience 48: 462-465, 2013.

Zhou T., Wang L., Sun X. et al.: Light intensity influence maize adaptation to low $\mathrm{P}$ stress by altering root morphology. - Plant Soil 447: 183-197, 2020.

Zhu H., Li X., Zhai W. et al.: Effects of low light on photosynthetic properties, antioxidant enzyme activity, and anthocyanin accumulation in purple pak-choi (Brassica campestris ssp. chinensis Makino). - PLoS ONE 12: e0179305, 2017.

Zhu Y., Gong H.: Beneficial effects of silicon on salt and drought tolerance in plants. - Agron. Sustain. Dev. 34: 455-472, 2014.

Zivcak M., Brestic M., Kalaji H.M., Govindjee: Photosynthetic responses of sun-and shade-grown barley leaves to high light: is the lower PSII connectivity in shade leaves associated with protection against excess of light? - Photosynth. Res. 119: 339-354, 2014b.

Zivcak M., Kalaji H.M., Shao H.-B. et al.: Photosynthetic proton and electron transport in wheat leaves under prolonged moderate drought stress. - J. Photoch. Photobio. B 137: 107115, 2014a.

(C) The authors. This is an open access article distributed under the terms of the Creative Commons BY-NC-ND Licence. 